Article

\title{
Synthesis and Antimalarial Activity of 1,4-Disubstituted Piperidine Derivatives
}

\author{
Rokhyatou Seck ${ }^{1}$, Abdoulaye Gassama ${ }^{1, *}$, Sandrine Cojean ${ }^{2,3}$ and Christian Cavé ${ }^{3, *}$ (D) \\ 1 Laboratoire de Chimie et Physique des Matériaux (LCPM), Université Assane SECK de Ziguinchor, \\ Ziguinchor BP 523, Senegal; seckrokhya@gmail.com \\ 2 Centre National de Référence du Paludisme, Hôpital Bichat-Claude Bernard, APHP, 75018 Paris, France; \\ sandrine.cojean@u-psud.fr \\ 3 Université Paris-Saclay, CNRS BioCIS, 92290 Châtenay-Malabry, France \\ * Correspondence: agassama@univ-zig.sn (A.G.); christian.cave@u-psud.fr (C.C.)
}

Received: 17 December 2019; Accepted: 10 January 2020; Published: 11 January 2020

check for updates

\begin{abstract}
In order to prepare, at low cost, new compounds active against Plasmodium falciparum, and with a less side-effects, we have designed and synthesized a library of 1,4-disubstituted piperidine derivatives from 4 -aminopiperidine derivatives 6 . The resulting compound library has been evaluated against chloroquine-sensitive (3D7) and chloroquine-resistant (W2) strains of $P$. falciparum. The most active molecules—compounds 12d (13.64 nM (3D7)), 13b (4.19 nM (3D7) and $13.30 \mathrm{nM}(\mathrm{W} 2))$, and 12a (11.6 nM (W2))—were comparable to chloroquine (22.38 nM (3D7) and $134.12 \mathrm{nM}(\mathrm{W} 2))$.
\end{abstract}

Keywords: piperidine; reductive amination; reagent-based diversity; antimalarial; drug lead

\section{Introduction}

This year's World Health Organization (WHO) report shows that after an unprecedented period of success in global malaria control, progress has stalled [1]. In 2016, there were an estimated 216 million cases of malaria, an increase of about 5 million cases over 2015. Deaths reached 445,000, a similar number to the previous year.

Malaria-related mortality followed the same trend, i.e., a decline from 2010 to 2014, and then an increase in 2015 and 2016. According to this report, it is in the WHO African region that the increase in cases of malaria and associated deaths was the most significant. The African region still accounts for some $90 \%$ of worldwide malaria cases and related deaths. Fifteen countries, all but one in sub-Saharan Africa, account for $80 \%$ of the global burden of malaria.

One of the biggest challenges facing malaria chemotherapy is the rapid emergence of resistance to existing antimalarial drugs [2]. Chloroquine was replaced as first line therapy by the sulfonamide antimalarials and, later on, artemisinin combination therapy (ACT), following the development of widespread resistance against the drug by Plasmodium falciparum [3]. This challenge underscores the need for the continued search for new antimalarials.

The 4-arylaminopiperidine is a structural moiety found in many alkaloids [4-11] and pharmaceutical products such as fentanyl and structurally-related analgesic opioids or H1-antihistamines agents such as bamipine [12-17] and neurokinin 1 (NK1) receptor antagonists [18-20]. Studies have shown that compounds with piperidine rings [4,8,21-26] have good selectivity and activity for the P. falciparum strain.

Research is being pursued for the discovery of new antimalarials with less side effects, a faster onset of action and a better rate of response [4,8,21-26]. In the process of searching for new small molecules interacting with the P. falciparum strain, we have identified the target compounds A with 
various R1, R2 and R3 substituents (Figure 1). In this paper, we describe the synthesis of some new derivatives with potential antimalarial properties.

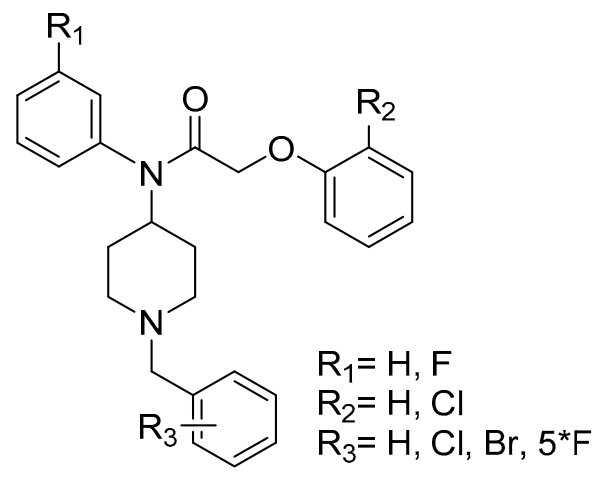

Figure 1. target compounds A.

\section{Results and Discussion}

\subsection{Chemistry}

The key compound 6 has been synthesized through a three-step process according to the Scheme 1 [27]. Thus, reductive amination [28-31] of $N$-boc-piperidin-4-one (1) with anilines $\mathbf{2 a}, \mathbf{b}$ in $\mathrm{CH}_{2} \mathrm{Cl}_{2}$, gave compounds $3 \mathbf{a}, \mathbf{b}$ in $75-85 \%$ yield. Acylation of the sodium salts of $\mathbf{3}$ with phenoxyacetyl chlorides 4 in $\mathrm{CH}_{2} \mathrm{Cl}_{2}$ at $0{ }^{\circ} \mathrm{C}$ furnished compounds 5 (85-90\%). Final deprotection $[32,33]$ of 5 using trifluoroacetic acid at room temperature provided compounds 6a-b (50-95\%) (Scheme 1).<smiles>[R]c1cccc(N)c1</smiles><smiles>[R]c1cccc(N(C(=O)COc2ccccc2[R2])C2CCN(C[R]([R9])([H])[H])CC2)c1</smiles>

$\mathrm{NaBH}(\mathrm{OAc})_{3} / \mathrm{AcOH}$ 1.2 dichloroethane

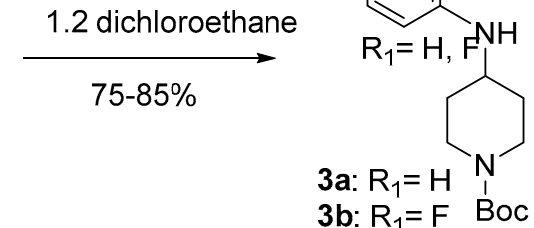

3b: $R_{1}=F$ Boc

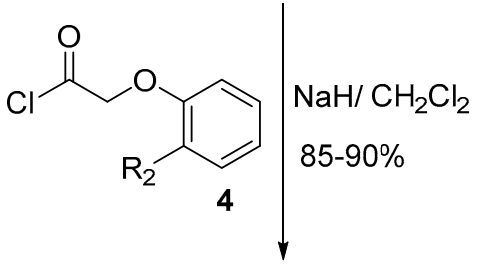

TFA $/ \mathrm{CH}_{2} \mathrm{Cl}_{2}$<smiles>[R]c1cccc(N(C(=O)COc2ccccc2[R])C2CCN(C(=O)OC(C)(C)C)CC2)c1</smiles>

5a: $R_{1}=H, R_{2}=H$

5b: $R_{1}=F, R_{2}=H$

Scheme 1. Synthesis of compounds $\mathbf{6 a}-\mathbf{b}$. 
The alkylation of 3 with the acetyl chloride supplied compounds 7 in $85 \%$ yield. The condensation of $\mathbf{7}$ with the phenol 8 gave compounds $\mathbf{9}(78-80 \%)$. Final deprotection $[32,33]$ of 9 using trifluoroacetic acid at room temperature provided compounds $\mathbf{6 c - d}$ (50-95\%) (Scheme 2). The Table 1 gives the overall yields of compounds $6 \mathbf{a}-\mathbf{d}$.

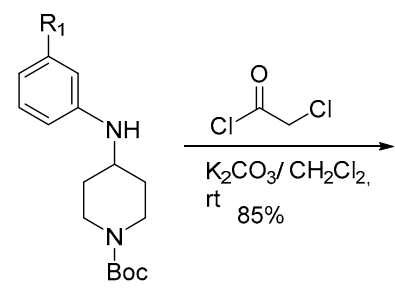

$3 a: R_{1}=H$ 3b: $R_{1}=F$

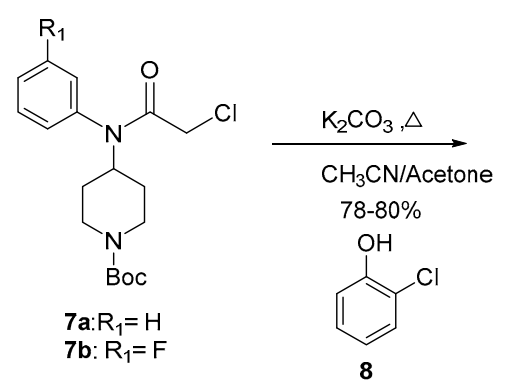

8<smiles>[R]c1cccc(N(C(=O)COc2ccccc2Cl)C2CCN(C(F)(F)F)CC2)c1</smiles>

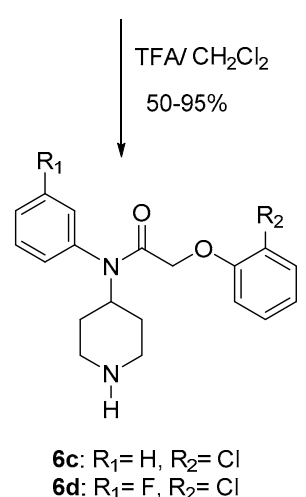

Scheme 2. Synthesis of compound $6 \mathrm{c}$ and $6 \mathrm{~d}$.

Table 1. The products of the synthesis of 6 recorded.

\begin{tabular}{llll}
\hline Compounds & $\mathbf{R}_{\mathbf{1}}$ & $\mathbf{R}_{\mathbf{2}}$ & Overall Yields \% \\
\hline 6a & $\mathrm{H}$ & $\mathrm{H}$ & 35 \\
6b & $\mathrm{F}$ & $\mathrm{H}$ & 34 \\
6c & $\mathrm{H}$ & $\mathrm{Cl}$ & 64 \\
6d & $\mathrm{F}$ & $\mathrm{Cl}$ & 33 \\
\hline
\end{tabular}

Condensation of phenoxyacetyl chloride with compound 3a in the presence of triethylamine at room temperature in acetone gave compounds 5a (55\%) and $\mathbf{1 0}(30 \%)$ (Scheme 3). In this reaction we used excess phenoxyacetyl chloride, and we think that this excess probably made the reaction medium acidic which cause the cleavage of the N-Boc protective group. To avoid this side reaction, we used $\mathrm{NaH}$ in $\mathrm{CH}_{2} \mathrm{Cl}_{2}$ which furnished compound $5 \mathbf{a}$ (Scheme 1).

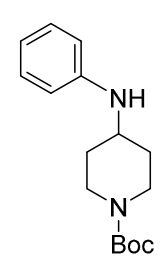

3a

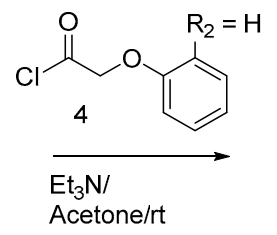

Acetone/rt
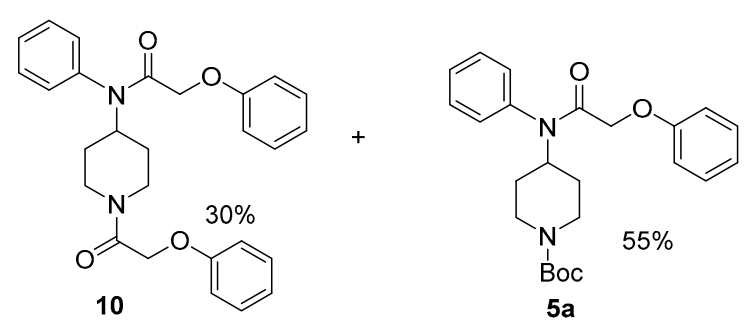

Scheme 3. Synthesis of compounds $5 \mathbf{a}$ and $\mathbf{1 0 .}$

A pharmaco-modulation has been achieved on the parent molecule 6 taking advantage of the nucleophilicity of the piperidine nitrogen leading to compounds 17-34 in good yield. Thus, reductive 
amination [28-31] of 6 with benzaldehyde derivatives in 1,2-dichloroethane $\left(\mathrm{ClCH}_{2} \mathrm{CH}_{2} \mathrm{Cl}\right)$, gave compounds A (Scheme 4) (Table 2).<smiles>[R]c1cccc(N(C(=O)COc2ccccc2[R])C2CCNCC2)c1</smiles>

6a: $R_{1}=H, R_{2}=H$ 6b: $R_{1}=F, R_{2}=H$ 6c: $\mathrm{R}_{1}=\mathrm{H}, \mathrm{R}_{2}=\mathrm{Cl}$ 6d: $R_{2}=F, R_{2}=C l$

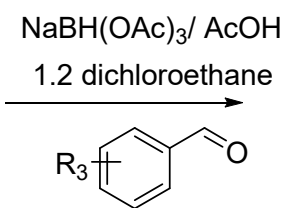

11
$\mathrm{R}_{3}=\mathrm{H}, \mathrm{Cl}, \mathrm{Br}, 5^{*} \mathrm{~F}$<smiles>[R]c1cccc(N(C(=O)COc2ccccc2[R2])C2CCN(Cc3cccc[R3]3[H])CC2)c1</smiles>

Scheme 4. Synthesis of target compounds A.

Table 2. The target compounds A.

\begin{tabular}{llllll}
\hline Compounds & $\mathbf{R}_{\mathbf{1}}$ & $\mathbf{R}_{\mathbf{2}}$ & $\mathbf{R}_{\mathbf{3}}$ & Time (h) & Overall Yields $\mathbf{\%}$ \\
\hline 12a & $\mathrm{H}$ & $\mathrm{H}$ & $\mathrm{H}$ & 24 & 18 \\
$\mathbf{1 2 b}$ & $\mathrm{F}$ & $\mathrm{H}$ & $\mathrm{H}$ & 24 & 18 \\
$\mathbf{1 2 c}$ & $\mathrm{H}$ & $\mathrm{Cl}$ & $\mathrm{H}$ & 24 & 32 \\
$\mathbf{1 2 d}$ & $\mathrm{F}$ & $\mathrm{Cl}$ & $\mathrm{H}$ & 24 & 18 \\
$\mathbf{1 3 a}$ & $\mathrm{H}$ & $\mathrm{H}$ & $\mathrm{Br}(o)$ & 24 & 21 \\
$\mathbf{1 3 b}$ & $\mathrm{F}$ & $\mathrm{H}$ & $\mathrm{Br}(o)$ & 24 & 19 \\
$\mathbf{1 3 c}$ & $\mathrm{H}$ & $\mathrm{Cl}$ & $\mathrm{Br}(o)$ & 24 & 35 \\
$\mathbf{1 3 d}$ & $\mathrm{F}$ & $\mathrm{Cl}$ & $\mathrm{Br}(o)$ & 24 & 20 \\
$\mathbf{1 4 a}$ & $\mathrm{H}$ & $\mathrm{H}$ & $\mathrm{Cl}(o)$ & 24 & 18 \\
$\mathbf{1 4 c}$ & $\mathrm{H}$ & $\mathrm{Cl}$ & $\mathrm{Cl}(o)$ & 24 & 41 \\
$\mathbf{1 4 d}$ & $\mathrm{F}$ & $\mathrm{Cl}$ & $\mathrm{Cl}(o)$ & 24 & 18 \\
$\mathbf{1 5 a}$ & $\mathrm{H}$ & $\mathrm{H}$ & $\mathrm{OH}(o), \mathrm{OH}(p)$ & 24 & 24 \\
$\mathbf{1 6 a}$ & $\mathrm{H}$ & $\mathrm{H}$ & $\mathrm{OH}(o), \mathrm{OMe}(o)$ & 24 & 18 \\
$\mathbf{1 7 a}$ & $\mathrm{H}$ & $\mathrm{H}$ & $5 \times \mathrm{F}(o, m, p)$ & 24 & 17 \\
$\mathbf{1 7 b}$ & $\mathrm{F}$ & $\mathrm{H}$ & $5 \times \mathrm{F}(o, m, p)$ & 24 & 18 \\
$\mathbf{1 7 c}$ & $\mathrm{H}$ & $\mathrm{Cl}$ & $5 \times \mathrm{F}(o, m, p)$ & 24 & 39 \\
$\mathbf{1 7 d}$ & $\mathrm{F}$ & $\mathrm{Cl}$ & $5 \times \mathrm{x}(o, m, p)$ & 24 & 20 \\
\hline
\end{tabular}

\subsection{The Antimalarial Activity of Derivatives $\mathbf{6}$ and Target Compounds $\mathbf{A}$}

Studies have shown that compounds with piperidine rings [4,8,21-26] have good selectivity and activity for the P. falciparum strain. This prompted us to assess their antiplasmodial activity against the chloroquine-sensitive 3D7 and chloroquine-resistant W2 strains of P. falciparum as well as their cytotoxic activity against HUVEC cells (Tables 3 and 4). Solutions of the 22 synthetic products and the negative control (chloroquine (CQ)) were prepared by two-fold dilution, in a dose-titration range of $0.098-100 \mu \mathrm{g} / \mathrm{mL}$, to obtain 11 concentrations each, and all of them were inactive against W2 $\left(\mathrm{IC}_{50}>100\right)$. The compounds exhibited activities in the nanomolar range against both parasitic strains. Their cytotoxicity against HUVEC ranged from $\mathrm{CC}_{50} 0.052 \pm 0.004$ to $>100 \mathrm{mM}$, thus resulting in varied selectivity indexes (SI), 26 for $13 \mathrm{~b}$ in the 3D7 strain and $>11.3$ for 14c in the W2 strain. Compared with chloroquine ( $\mathrm{IC}_{50}=22.38(3 \mathrm{D} 7)$ and $\left.134.12(\mathrm{~W} 2)\right)$, the compounds $\mathbf{1 3 b}\left(\mathrm{IC}_{50}=13.30 \mathrm{nM}\right)$ and 12a $\left(\mathrm{IC}_{50}=11.06 \mathrm{nM}\right)$ showed a strong activity against W2. Molecules $\mathbf{1 3 b}\left(\mathrm{IC}_{50}=4.19 \mathrm{nM}\right), \mathbf{1 2 d}$ $\left(\mathrm{IC}_{50}=13.64 \mathrm{nM}\right), \mathbf{1 4 d}\left(\mathrm{IC}_{50}=14.85 \mathrm{nM}\right)$ and $\mathbf{6 b}\left(\mathrm{IC}_{50}=17,42 \mathrm{nM}\right)$ had the highest activity against 3D7.

Interestingly, compounds $\mathbf{6 c}$ and $\mathbf{6 d}$ are inactive against both strains. However, after pharmacomodulation on the nitrogen atom, their derivatives $12 \mathrm{~d}, 14 \mathrm{~d}, 17 \mathrm{c}, 13 \mathrm{c}$ and $14 \mathrm{c}$ showed good activity against both strains. 
Compound 13b exhibits 5-fold more activity against strain 3D7 and 10-fold more against strain W2 with very low cytotoxicity $\left(\mathrm{CC}_{50}=112 \mathrm{nM}\right)$, resulting in a high selectivity index $(\mathrm{SI}=26.7$ (3D7) and 8.4 (W2), respectively) relative to chloroquine $\left(\mathrm{CC}_{50}=37.56 \mathrm{nM}, \mathrm{SI}=1.7(3 \mathrm{D} 7)\right.$ and $\left.0.3(\mathrm{~W} 2)\right)$.

Substitution of the piperidine nitrogen atom with a pentafluorobenzyl moiety did not significantly alter the activity of its derivative molecules against both strains. Indeed, the compounds $\mathbf{1 7 b}$ and $\mathbf{1 7 d}$, derived from $\mathbf{6 b}$ and $\mathbf{6 d}$, respectively, remained inactive while the activity of $\mathbf{1 7 a}(37.63 \mathrm{nM}(3 \mathrm{D} 7)$ and $47.84 \mathrm{nM}(\mathrm{W} 2))$ and 17c (14.65 nM (3D7) and $36.88 \mathrm{nM}(\mathrm{W} 2))$ respectively, and 6a (34.46 nM (3D7) and $61.37 \mathrm{nM}(\mathrm{W} 2))$ and 6c (17.42 $\mathrm{nM}(3 \mathrm{D} 7)$ and $30.35 \mathrm{nM}(\mathrm{W} 2))$ varied slightly.

Table 3. The antimalarial activity of compounds derivatives 6.

\begin{tabular}{l|l|l|l|l|l}
\hline & $\begin{array}{l}\text { Plasmodium } \\
\text { falciparum 3D7 } \\
\text { Strain }\end{array}$ & $\begin{array}{l}\text { Plasmodium } \\
\text { falciparum } \mathbf{W 2} \\
\text { Strain }\end{array}$ & HUVEC Cells & $\begin{array}{l}\text { Selectivity } \\
\text { Index (3D7) }\end{array}$ & $\begin{array}{l}\text { Selectivity } \\
\text { Index (W2) }\end{array}$ \\
\hline Compounds & IC50 \pm SD (nM) & $\mathbf{I C}_{\mathbf{5 0}} \pm \mathbf{S D}$ (nM) & $\mathbf{C C}_{\mathbf{5 0}} \mathbf{n M} \mathbf{\text { SD }}$ & $\mathbf{= C C}_{\mathbf{5 0}} / \mathbf{I C}_{\mathbf{5 0}}$ & $=\mathbf{C C}_{\mathbf{5 0}} / \mathbf{I C}_{\mathbf{5 0}}$ \\
\hline $\mathbf{6 a}$ & $34.46 \pm 9.25$ & $61.37 \pm 11.12$ & $\mathrm{nd}$ & $\mathrm{nd}$ & $\mathrm{nd}$ \\
$\mathbf{6 b}$ & $17.42 \pm 7.7$ & $30.35 \pm 6.09$ & $>100$ & $>17.5$ & $>10.8$ \\
$\mathbf{6 c}$ & $>100$ & $>100$ & $/$ & $/$ & $/$ \\
$\mathbf{6 d}$ & $>100$ & $>100$ & $/$ & $/$ & $/$ \\
$\mathbf{C Q}$ & $22.38 \pm 3.24$ & $134.12 \pm 32.29$ & $37.56 \pm 1.24$ & 1.7 & 0.3 \\
\hline
\end{tabular}

Table 4. The antimalarial activity of the target compounds.

\begin{tabular}{|c|c|c|c|c|c|}
\hline & $\begin{array}{l}\text { Plasmodium } \\
\text { falciparum 3D7 } \\
\text { Strain }\end{array}$ & $\begin{array}{l}\text { Plasmodium } \\
\text { falciparum W2 } \\
\text { Strain }\end{array}$ & HUVEC Cells & $\begin{array}{l}\text { Selectivity } \\
\text { Index (3D7) }\end{array}$ & $\begin{array}{l}\text { Selectivity } \\
\text { Index (W2) }\end{array}$ \\
\hline Compounds & $\mathrm{IC}_{50} \pm \mathrm{SD}(\mathrm{nM})$ & $\mathrm{IC}_{50} \pm \mathrm{SD}(\mathrm{nM})$ & $\mathrm{CC}_{50} \mathrm{nM} \pm \mathrm{SD}$ & $=\mathrm{CC}_{50} / \mathrm{IC}_{50}$ & $=\mathrm{CC}_{50} / \mathrm{IC}_{50}$ \\
\hline 10 & $25.37 \pm 2.88$ & $42.14 \pm 6.73$ & $>100$ & $>8.9$ & $>5.3$ \\
\hline $12 a$ & $36.9 \pm 6.59$ & $11.06 \pm 4.82$ & $100 \pm 0.008$ & 2.85 & 5.7 \\
\hline $12 b$ & $34.45 \pm 7.36$ & $38.95 \pm 3.66$ & $>100$ & $>6.9$ & $>6.1$ \\
\hline $12 \mathrm{c}$ & $>100$ & $>100$ & / & / & / \\
\hline $12 d$ & $13.64 \pm 2.47$ & $166.87 \pm 9.64$ & nd & nd & nd \\
\hline $13 a$ & $>100$ & $>100$ & / & / & l \\
\hline $13 b$ & $4.19 \pm 1.12$ & $13.30 \pm 2.01$ & $112 \pm 0.008$ & 26.7 & 8.4 \\
\hline $13 c$ & $44.17 \pm 3.9$ & $28.57 \pm 1.91$ & $>100$ & $>4.4$ & $>6.8$ \\
\hline $13 d$ & $>100$ & $>100$ & / & / & 1 \\
\hline $14 a$ & $20.72 \pm 7.69$ & $32.33 \pm 9.97$ & $52 \pm 0.004$ & 2.5 & 1.6 \\
\hline $14 c$ & $50.33 \pm 3.8$ & $18.97 \pm 7.30$ & $>100$ & $>4.2$ & $>11.3$ \\
\hline 14d & $14.85 \pm 4.48$ & $23.45 \pm 4.66$ & $100 \pm 0.005$ & 6.83 & 4.3 \\
\hline $15 a$ & $>100$ & $>100$ & / & / & / \\
\hline $16 a$ & $>100$ & $>100$ & / & / & / \\
\hline $17 a$ & $37.63 \pm 7.85$ & $47.84 \pm 5.83$ & nd & nd & nd \\
\hline $17 \mathrm{~b}$ & $>100$ & $>100$ & / & / & l \\
\hline $17 \mathrm{c}$ & $14.65 \pm 2.55$ & $36.88 \pm 2.99561$ & nd & nd & nd \\
\hline $17 d$ & $>100$ & $>100$ & / & / & l \\
\hline CQ & $22.38 \pm 3.24$ & $134.12 \pm 32.29$ & $37.56 \pm 1.24$ & 1.7 & 0.3 \\
\hline
\end{tabular}

\section{Materials and Methods}

\subsection{Apparatus, Materials, and Analytical Reagents}

All chemical reagents and anhydrous solvents were obtained from commercial sources and used without further purification. The ${ }^{1} \mathrm{H}$ - and ${ }^{13} \mathrm{C}-\mathrm{NMR}$ spectra were recorded in $\mathrm{CDCl}_{3}$ at ambient temperature on an AMX 500 spectrometer (Bruker, Palaiseau, France). Some product structures were confirmed by DEPT 135, HMQC and HMBC experiments. Chemical shifts are given in $\delta$ (ppm) and coupling constants $J(\mathrm{~Hz})$ relative to TMS used as internal standard; multiplicities were recorded as s (singlet), d (doublet), dd (double doublet), $\mathrm{t}$ (triplet), $\mathrm{dt}$ (double triple), $\mathrm{q}$ (quartet) or 
$\mathrm{m}$ (multiplet). Reactions involving anhydrous conditions were conducted in dry glassware under a nitrogen atmosphere. The infrared spectra have been recorded on a model 842 spectrometer (Perkin-Elmer, 842) using polystyrene as reference. The melting points have been measured on a Tottoli S Bucchi device (Buchi, Rungis, France). Microanalysis have been done on a Perkin-Elmer 2400-CMN apparatus (Perkin ElmerVillebon-sur-Yvette, France). GC/MS conditions: Analyses were performed using a 5890 gas chromatogram connected to a G 1019 A mass spectrometer (both from Hewlett Packard, Alpharetta, GA, USA) operating in the electrospray ionization mode (ESI).

\subsection{Chemistry}

3.2.1. General procedure for the Synthesis of tert-Butyl 4-(phenylamino) Piperidine-1-carboxylates $3 \mathbf{a}-\mathbf{b}$

A solution of aniline (1 equiv) in 1,2-dichloroethane (100 mL) containing t-butyl-4-oxo-1-piperidine carboxylate (1 equiv), sodium triacetoxyborohydride (1.5 equiv) and acetic acid (1.5 equiv) was stirred for $24 \mathrm{~h}$ at $20^{\circ} \mathrm{C}$. $1 \mathrm{~N} \mathrm{NaOH}(50 \mathrm{~mL}, 50 \mathrm{mmol})$ and $50 \mathrm{~mL}$ of ethyl acetate were added. The phases were separated and the aqueous layer was extracted with ethyl acetate $(3 \times 25 \mathrm{~mL})$. The combined organic layers were dried over $\mathrm{MgSO}_{4}$, filtered and concentrated under reduced pressure. The residue was purified by crystallization (ether petroleum/ethyl acetate (8:2)).

tert-Butyl 4-(phenylamino) piperidine-1-carboxylate (3a). Aniline $(2.8 \mathrm{~g}, 30.11 \mathrm{mmol})$ in 1.2-dichloroethane $(100 \mathrm{~mL})$ containing t-butyl-4-oxo-1-piperidine carboxylate $(6 \mathrm{~g}, 30.11 \mathrm{mmol})$, sodium triacetoxyborohydride $(9.57 \mathrm{~g}, 45.1 \mathrm{mmol})$ and acetic acid $(2.71 \mathrm{~g}, 45.16 \mathrm{mmol})$ gave compound $3 \mathrm{a}(7.07 \mathrm{~g}, 85 \%)$, m.p.: $105^{\circ} \mathrm{C}$. ${ }^{1} \mathrm{H}-\mathrm{NMR}\left(\mathrm{CDCl}_{3}\right): 1.3\left(\mathrm{~m}, 2 \mathrm{H}, \mathrm{CH}_{2}\right) ; 1.49\left(\mathrm{~s}, 9 \mathrm{H}, 3 \mathrm{CH}_{3}\right) ; 2.0\left(\mathrm{~m}, 2 \mathrm{H}, \mathrm{CH}_{2}\right) ; 2.9\left(\mathrm{~m}, 2 \mathrm{H}, \mathrm{CH}_{2}\right) ; 3.3(\mathrm{~m}, 1 \mathrm{H}$, $\mathrm{CH}) ; 3.7$ (broadband, $1 \mathrm{H}, \mathrm{NH}) ; 4.1(\mathrm{~m}, 2 \mathrm{H}, \mathrm{CH} 2) ; 6.5-7.5$ (m, 5H aromatic). ${ }^{13} \mathrm{C}-\mathrm{NMR}\left(\mathrm{CDCl}_{3}\right) \delta: 28.57$ $\left(3 \times \mathrm{CH}_{3}\right) ; 32.52\left(2 \times \mathrm{CH}_{2}\right) ; 42.30\left(2 \times \mathrm{CH}_{2}\right) ; 50.22(\mathrm{CH}) ; 79.72(\mathrm{C}) ; 113.42$ (2× CHAr); 117.61 (CHAr); 129.49 (2× CHAr); 149.89 (C); 154.92 (C). MS (m/z): calcd. for $\mathrm{C}_{16} \mathrm{H}_{24} \mathrm{~N}_{2} \mathrm{O}_{2} 276.2$ found 277.1 [M + 1]; IR cm ${ }^{-1}$ : 1763.07 (CO carbamate); 1671.6 (CO, amide).

tert-Butyl 4-(3-fluorophenylamino) piperidine-1-carboxylate (3b). 3-Fluoroaniline (3.34 g, $30.11 \mathrm{mmol})$ in 1,2-dichloroethane $(100 \mathrm{~mL})$ containing t-butyl-4-oxo-1-piperidine carboxylate $(6 \mathrm{~g}, 30.11 \mathrm{mmol})$, sodium triacetoxyborohydride $(9.57 \mathrm{~g}, 45.1 \mathrm{mmol})$ and acetic acid $(2.71 \mathrm{~g}, 45.16 \mathrm{mmol})$ gave compound $3 \mathbf{b}\left(6.58\right.$ g, 74\%); m.p.: $114{ }^{\circ} \mathrm{C} .{ }^{1} \mathrm{H}-\mathrm{NMR}\left(\mathrm{CDCl}_{3}\right): 1.3\left(\mathrm{~m}, 2 \mathrm{H}, \mathrm{CH}_{2}\right) ; 1.49\left(\mathrm{~s}, 9 \mathrm{H}, 3 \mathrm{CH}_{3}\right) ; 2.0(\mathrm{~m}, 2 \mathrm{H}$, $\left.\mathrm{CH}_{2}\right) ; 2.9\left(\mathrm{~m}, 2 \mathrm{H}, \mathrm{CH}_{2}\right) ; 3,4(\mathrm{~m}, 1 \mathrm{H}, \mathrm{CH}) ; 3.8$ broad band, $\left.1 \mathrm{H}, \mathrm{NH}\right) ; 4.1\left(\mathrm{~m}, 2 \mathrm{H}, \mathrm{CH}_{2}\right) ; 6.5-7.5(\mathrm{~m}, 4 \mathrm{H}$ aromatic). ${ }^{13} \mathrm{C}-\mathrm{NMR}\left(\mathrm{CDCl}_{3}\right) \delta: 28.56\left(3 \times \mathrm{CH}_{3}\right) ; 32.36\left(2 \times \mathrm{CH}_{2}\right) ; 42.73\left(2 \times \mathrm{CH}_{2}\right) ; 50.26(\mathrm{CH}) ; 79.81(\mathrm{C})$; 99.95 (d, J = 25.26 Hz, CHAr); 103.84 (d, J = 21.25 Hz, CHAr); 109.19 (d, J = 2.2 Hz, CHAr); 130.58 (d, $J=10.30 \mathrm{~Hz}, \mathrm{CHAr}) ; 148.73(\mathrm{~d}, J=10.55 \mathrm{~Hz}, \mathrm{C}) ; 154.896(\mathrm{C}), 163.34(\mathrm{~d}, J=242.72 \mathrm{~Hz}, \mathrm{C})$. ESI $(\mathrm{m} / \mathrm{z}) \mathrm{calcd}$ for $\mathrm{C}_{16} \mathrm{H}_{23} \mathrm{FN}_{2} \mathrm{O}_{2}$ 294.2; found 294.1 [M + 1]; IR cm ${ }^{-1}$ : 1760.07 (CO carbamate); 1670.6 (CO, amide).

\subsubsection{General Procedure for the Coupling with Phenoxyacetyl chloride: Synthesis of Compounds 5a-b}

To an ice-cooled suspension of sodium hydride (60\% in mineral oil, 2 equiv) in $\mathrm{CH}_{2} \mathrm{Cl}_{2}$ (10 mL) was added dropwise a solution of compound 3 (1 equiv), in $\mathrm{CH}_{2} \mathrm{Cl}_{2}(15 \mathrm{~mL})$. After stirring $15 \mathrm{~min}$ phenoxyacetyl chloride 4 ( 2 equiv) was added. The reaction mixture was stirred for $1 \mathrm{~h}$ at $0{ }^{\circ} \mathrm{C}$, and the temperature was raised to room temperature during $3 \mathrm{~h}$. $20 \mathrm{~mL}$ of saturated solution of $\mathrm{NaHCO}_{3}$ was carefully added. The aqueous layer was extracted with $\mathrm{CH}_{2} \mathrm{Cl}_{2}(3 \times 20 \mathrm{~mL})$. The combined organic phases were dried over $\mathrm{MgSO}_{4}$, and concentrated in vacuum. The crude product was purified by crystallisation (ether petroleum/ethyl acetate (8:2)).

tert-Butyl 4-(2-phenoxy-N-phenylacetamido) piperidine-1-carboxylate (5a). Following the general procedure, sodium hydride (60\% in mineral oil, $0.723 \mathrm{~g}, 18.1 \mathrm{mmol})$ in $\mathrm{CH}_{2} \mathrm{Cl}_{2}(10 \mathrm{~mL})$ was added dropwise a solution of compound $3 \mathrm{a}(2.5 \mathrm{~g}, 9.05 \mathrm{mmol})$, in $\mathrm{CH}_{2} \mathrm{Cl}_{2}(15 \mathrm{~mL})$. After stirring $15 \mathrm{~min}$ phenoxyacetyl chloride $(2.5 \mathrm{~mL}, 18.1 \mathrm{mmol})$ was added to give compound $5 \mathrm{a}(3.06 \mathrm{~g}, 82 \%) .{ }^{1} \mathrm{H}-\mathrm{NMR}\left(\mathrm{CDCl}_{3}\right): 1.25$ $\left(\mathrm{m}, 2 \mathrm{H}, \mathrm{CH}_{2}\right) ; 1.4(\mathrm{~s}, 9 \mathrm{H}) ; 1.8\left(\mathrm{~m}, 2 \mathrm{H}, \mathrm{CH}_{2}\right) ; 2.9\left(\mathrm{~m}, 2 \mathrm{H}, \mathrm{CH}_{2}\right) ; 4.1\left(\mathrm{~m}, 2 \mathrm{H}, \mathrm{CH}_{2}\right) ; 4.25\left(\mathrm{~m}, 2 \mathrm{H}, \mathrm{CH}_{2}\right) ; 4.8$ 
(m, 1H, CH); 6.7-7.5 (m, 10H aromatic). ${ }^{13} \mathrm{C}-\mathrm{NMR}\left(\mathrm{CDCl}_{3}\right)$ 8: $28.456\left(3 \times \mathrm{CH}_{3}, \mathrm{C}\left(\mathrm{CH}_{3}\right)_{3}\right) ; 30.32(2 \times$ $\left.\mathrm{CH}_{2}\right) ; 43.315\left(2 \times \mathrm{CH}_{2}\right) ; 52.96(\mathrm{CH}) ; 66.7(\mathrm{CH} 2) ; 79.73(\mathrm{C}) ; 114.8$ (2× CHAr); $121.47(\mathrm{CHAr}) ; 129.34(\mathrm{CH})$; 129.46 (2× CHAr); 129.88 (2× CHAr); 130.09 (2× CHAr); 136.89 (C); 154.63 (C); 158.14 (C); 167.6 (C). ESI $(\mathrm{m} / \mathrm{z})$ calcd for $\mathrm{C} 24 \mathrm{H} 30 \mathrm{~N} 2 \mathrm{O} 4$ 410, 2 found 411.1 [M + 1], $\mathrm{IR} \mathrm{cm}^{-1}: 1744.95$ (CO carbamate); 1652.06 (CO, amide).

tert-Butyl 4-(N-(3-fluorophenyl)-2-phenoxyacetamido) piperidine-1-carboxylate (5b). Following the general procedure, sodium hydride ( $60 \%$ in mineral oil, $0.677 \mathrm{~g}, 16.93 \mathrm{mmol})$ in $\mathrm{CH}_{2} \mathrm{Cl}_{2}(10 \mathrm{~mL})$ was added dropwise a solution of compound $3 \mathbf{b}(2.49 \mathrm{~g}, 8.46 \mathrm{mmol})$, in $\mathrm{CH}_{2} \mathrm{Cl}_{2}(15 \mathrm{~mL})$. After stirring $15 \mathrm{~min}$ phenoxyacetyl chloride $(2.88 \mathrm{~g}, 16.93 \mathrm{mmol})$ was added to give compound $5 \mathbf{b}(2.34 \mathrm{~g}, 65 \%) .{ }^{1} \mathrm{H}-\mathrm{NMR}$ $\left(\mathrm{CDCl}_{3}\right): 1.25\left(\mathrm{~m}, 2 \mathrm{H}, \mathrm{CH}_{2}\right) ; 1.4\left(\mathrm{~s}, 9 \mathrm{H}, 3 \times \mathrm{CH}_{3}\right) ; 1.8\left(\mathrm{~d}, 2 \mathrm{H}, \mathrm{CH}_{2}\right) ; 2.8\left(\mathrm{~m}, 2 \mathrm{H}, \mathrm{CH}_{2}\right) ; 4.15\left(\mathrm{~m}, 2 \mathrm{H}, \mathrm{CH}_{2}\right)$; $4.30\left(\mathrm{~s}, 2 \mathrm{H}, \mathrm{CH}_{2}\right) ; 4.75(\mathrm{~m}, \mathrm{H}, \mathrm{CH}) ; 6.7-7.6\left(\mathrm{~m}, 9 \mathrm{H}\right.$ aromatic). ${ }^{13} \mathrm{C}-\mathrm{NMR}\left(\mathrm{CDCl}_{3}\right) \delta: 28.44\left(3 \times \mathrm{CH}_{3}\right.$, $\left.\mathrm{C}\left(\mathrm{CH}_{3}\right)_{3}\right) ; 30.284\left(2 \times \mathrm{CH}_{2}\right) ; 43.16\left(2 \times \mathrm{CH}_{2}\right) ; 53.188(\mathrm{CH}) ; 66.82\left(\mathrm{CH}_{2}\right) ; 79.81(\mathrm{C}) ; 114.76(2 \times \mathrm{CHAr})$; 116.53 (d, $J=20.74 \mathrm{~Hz}, \mathrm{CHAr}) ; 117.63$ (d, J = 21.49 Hz, CHAr); 121.60 (CHAr); 125.97 (d, J = 3.14 Hz, CHAr); 129.50 (2× CHAr);130.92 (d, J = 7.3 Hz, CHAr); 138.52 (d, J = 9.17 Hz, C); 154.58 (C); 157.97 (C); $161.91(\mathrm{~d}, J=250.14 \mathrm{~Hz}, \mathrm{C}) ; 167.19(\mathrm{C})$. ESI $(\mathrm{m} / \mathrm{z})$ : calcd for $\mathrm{C}_{24} \mathrm{H}_{29} \mathrm{FN}_{2} \mathrm{O}_{4} 428.2$, found 429.0 [M + 1]; IR $\mathrm{cm}^{-1}: 1745.07$ (CO carbamate); 1660.6 (CO, amide).

\subsubsection{General Procedure for the Coupling with Chloroacetyl chloride: Synthesis of Compounds 7a-b}

One equiv of compound 3 was dissolved in $25 \mathrm{~mL}$ of $\mathrm{CH}_{2} \mathrm{Cl}_{2}, 2$ equiv. of potassium carbonate were added and the mixture was cooled to $0^{\circ} \mathrm{C}$. Two equiv. of chloroacetyl chloride were added to $0{ }^{\circ} \mathrm{C}$, and the mixture was stirred overnight. The reaction was quenched by addition of a saturated solution of $\mathrm{NaHCO}_{3}(25 \mathrm{~mL})$, the aqueous phase was decanted and extracted twice with $15 \mathrm{~mL}$ of $\mathrm{CH}_{2} \mathrm{Cl}_{2}$. Combined organic phases were washed with water and brine, dried over $\mathrm{MgSO}_{4}$ and concentrated in vacuum. The crude product was purified by crystallisation (ether petroleum/ethyl acetate (8:2)).

tert-Butyl-4-(2-chloro-N-phenylacetamido) piperidine-1-carboxylate (7a). Following the general procedure, $2.5 \mathrm{~g}$ (9.03 mmol) of compound 3a were dissolved in $25 \mathrm{~mL}$ of $\mathrm{CH}_{2} \mathrm{Cl}_{2}, 2.5 \mathrm{~g}$ (18.06 mmol) of potassium carbonate were added and the mixture was cooled to $0{ }^{\circ} \mathrm{C} .2 .04 \mathrm{~g}(18.06 \mathrm{mmol})$ of chloroacetyl chloride were added, and the mixture was stirred overnight to afford $7 \mathbf{a}$ as a white solid ( $2.55 \mathrm{~g}, 80 \%)$, m.p.: $110^{\circ} \mathrm{C}$. 1H-NMR (CDCl3, $\left.500 \mathrm{MHz}\right): 1.25$ (m, 2H, CH2); 1.4 (s, $\left.9 \mathrm{H}, 3 \times \mathrm{CH} 3\right) ; 1.8$ (m, 2H, CH2); 3.7 (s, 2H, CH2); 2.8 (m, 2H, CH2); 4.1 (m, 2H, CH2); 4.75 (m, 1H, CH); 7-7.5 (m, 5H aromatic). ${ }^{13} \mathrm{C}-\mathrm{NMR}$

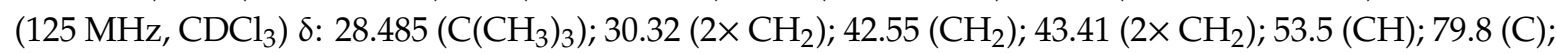
129.47 (2× CHAr); 129.9 (CHAr); $130.2(2 \times \mathrm{CH}) ; 137.3$ (C); 154.64 (C); 166.04 (C). ESI ( $\mathrm{m} / \mathrm{z})$ : calcd for $\mathrm{C}_{18} \mathrm{H}_{25} \mathrm{ClN}_{2} \mathrm{O}_{3}$ 352.2, found 353.0 [M + 1]; IR cm ${ }^{-1}$ : 1730.5 (CO carbamate); 1699.03 (CO, amide).

tert-Butyl 4-(2-chloro-N-(3-fluorophenyl) acetamido)piperidine-1-carboxylate (7b). Following the general procedure, $2.5 \mathrm{~g}(8.46 \mathrm{mmol})$ of compound $3 \mathbf{b}$ were dissolved in $25 \mathrm{~mL}$ of $\mathrm{CH}_{2} \mathrm{Cl}_{2}$, then $2.34 \mathrm{~g}$ $(16.93 \mathrm{mmol})$ of potassium carbonate were added and the mixture was cooled to $0{ }^{\circ} \mathrm{C}$. Chloroacetyl chloride $(1.91 \mathrm{~g}, 18.06 \mathrm{mmol})$ was added, and the mixture was stirred overnight to afford $7 \mathrm{~b}(2.66 \mathrm{~g}$, 85\%), m.p.: $90{ }^{\circ} \mathrm{C} .{ }^{1} \mathrm{H}-\mathrm{NMR}\left(\mathrm{CDCl}_{3}, 500 \mathrm{MHz}\right): 1.25\left(\mathrm{~m}, 2 \mathrm{H}, \mathrm{CH}_{2}\right) ; 1.4\left(\mathrm{~s}, 9 \mathrm{H}, 3 \mathrm{CH}_{3}\right) ; 1.8(\mathrm{~m}, 2 \mathrm{H}$, $\left.\mathrm{CH}_{2}\right) ; 3.7\left(\mathrm{~s}, 2 \mathrm{H}, \mathrm{CH}_{2}\right) ; 2.8\left(\mathrm{~m}, 2 \mathrm{H}, \mathrm{CH}_{2}\right) ; 4.1\left(\mathrm{~m}, 2 \mathrm{H}, \mathrm{CH}_{2}\right) ; 4.75(\mathrm{~m}, 1 \mathrm{H}, \mathrm{CH}) ; 7-7.5(\mathrm{~m}, 5 \mathrm{H}$ aromatic). ${ }^{13} \mathrm{C}$-NMR (125 MHz, CDCl 3 ) 8: $28.44\left(3 \times \mathrm{CH}_{3}\right) ; 30.27\left(2 \times \mathrm{CH}_{2}\right) ; 42.26\left(\mathrm{CH}_{2}\right) ; 42.97\left(2 \times \mathrm{CH}_{2}\right) ; 53.69$ (CH); 79.878 (C); 116.72 (d, J = 20.74 Hz, CHAr); 117.79 (d, J = 21.49 Hz, CHAr); 126.14 (CHAr); 131.08 (d, J = 9.17 Hz, CHAr); $138.8(\mathrm{~d}, J=9.17 \mathrm{~Hz}, \mathrm{C}) ; 154.58(\mathrm{C}) ; 161.926(\mathrm{C}) ; 163.92(\mathrm{~d}, J=234,80 \mathrm{~Hz}, \mathrm{C})$. ESI (m/z): calcd for $\mathrm{C}_{18} \mathrm{H}_{24} \mathrm{ClFN}_{2} \mathrm{O}_{3} 370.1$ found 371.0 [M + 1]; IR cm ${ }^{-1}$ : 1730.5 (CO carbamate); 1699.08 (CO, amide).

\subsubsection{General Procedure for Synthesis of Compounds $\mathbf{9 a - b}$}

To a mixed solution of acetonitrile/acetone (50/50) were added 1 equiv of compound $7 ; 1$ equiv of 2-chlorophenol and 2 equiv of potassium carbonate. After $12 \mathrm{~h}$ of stirring under reflux the mixture was concentrated in vacuum. The residual was dissolved in $15 \mathrm{~mL}$ of ethyl acetate and $(1 \mathrm{~N})$ of $\mathrm{NaOH}$ 
(15 mL), the aqueous phase was decanted and extracted twice with $15 \mathrm{~mL}$ of ethyl acetate. Combined organic phases were washed with water and brine, dried over $\mathrm{MgSO}_{4}$ and concentrated in vacuum. The crude product was purified by crystallisation (ether petroleum/ethyl acetate (8:2)).

tert-Butyl 4-(2-(2-chlorophenoxy)-N-phenylacetamido) piperidine-1-carboxylate (9a). Following the general procedure, $2.83 \mathrm{~g}(8.04 \mathrm{mmol})$ of compound $7 ; 1.032 \mathrm{~g}(8.04 \mathrm{mmol})$ of 2-chlorophenol and $2.22 \mathrm{~g}$ (16.09 mmol) of potassium carbonate. (3.57 g, 99\%); m.p.: $123{ }^{\circ} \mathrm{C} ;{ }^{1} \mathrm{H}-\mathrm{NMR}\left(\mathrm{CDCl}_{3}, 600 \mathrm{MHz}\right): 1.3$ $(\mathrm{m}, 2 \mathrm{H}, \mathrm{CH} 2) ; 1.5\left(\mathrm{~s}, 9 \mathrm{H}, 3 \times \mathrm{CH}_{3}\right) ; 1.80\left(\mathrm{~m}, 2 \mathrm{H}, \mathrm{CH}_{2}\right) ; 2.85\left(\mathrm{~m}, 2 \mathrm{H}, \mathrm{CH}_{2}\right) ; 4.12(\mathrm{~m}, 1 \mathrm{H}, \mathrm{CH}) ; 4.33(\mathrm{~s}$, $2 \mathrm{H}, \mathrm{CH} 2) ; 4.76$ (m, H, CH); 6.4-7.5 (m, 9H aromatic). ${ }^{13} \mathrm{C}-\mathrm{NMR}\left(150 \mathrm{MHz}, \mathrm{CDCl}_{3}\right) \delta: 28.46\left(3 \times \mathrm{CH}_{3}\right)$; $29.83\left(2 \times \mathrm{CH}_{2}\right) ; 42.75\left(2 \times \mathrm{CH}_{2}\right) 53.04(\mathrm{CH}) ; 67.62\left(\mathrm{CH}_{2}\right) ; 79.78(\mathrm{C}) ; 113.95(2 \times \mathrm{CHAr}) ; 122.27(2 \times \mathrm{CHAr})$; 123.27 (C); 127.61 (CHAr); 129.45(CHAr); 129.97 (CHAr); 130.14 (CHAr); 130.45 (CHAr); 136.64 (C); $153.9(\mathrm{C}) ; 154.64(\mathrm{C}) ; 166.84(\mathrm{C})$. ESI $(\mathrm{m} / \mathrm{z})$ : calcd for $\mathrm{C}_{24} \mathrm{H}_{29} \mathrm{ClN}_{2} \mathrm{O}_{4} 444.1$, found $445.0[\mathrm{M}+1] ; \mathrm{IR} \mathrm{cm}^{-1}$ : 1727.5 (CO carbamate); 1693.33 (CO, amide).

tert-Butyl 4-(2-(2-chlorophenoxy)-N-(3-fluorophenyl) acetamido) piperidine-1-carboxylate (9b). Following the general procedure, $1.80 \mathrm{~g}(4.87 \mathrm{mmol})$ of compound $7 ; 0.626 \mathrm{~g}(4.87 \mathrm{mmol})$ of 2-chlorophenol and 1.34 $\mathrm{g}(9.75 \mathrm{mmol})$ of potassium carbonate were reacted to give $9 \mathrm{~b}(2.01 \mathrm{~g}, 89 \%) ; \mathrm{m} . \mathrm{p} .: 125^{\circ} \mathrm{C} ;{ }^{1} \mathrm{H}-\mathrm{NMR}$ $\left(\mathrm{CDCl}_{3}, 500 \mathrm{MHz}\right): 1.18\left(\mathrm{~m}, 2 \mathrm{H}, \mathrm{CH}_{2}\right) ; 1.21\left(\mathrm{~s}, 9 \mathrm{H}, 3 \mathrm{CH}_{3}\right) ; 1.74\left(\mathrm{~m}, 2 \mathrm{H}, \mathrm{CH}_{2}\right) ; 2.71(\mathrm{t}, J=12 \mathrm{~Hz}, 2 \mathrm{H}$, $\left.\mathrm{CH}_{2}\right) ; 4.06\left(\mathrm{~m}, 2 \mathrm{H}, \mathrm{CH}_{2}\right) ; 4.31\left(\mathrm{~s}, 2 \mathrm{H}, \mathrm{CH}_{2}\right) ; 4.67(\mathrm{~m}, 1 \mathrm{H}, \mathrm{CH}) 6.4-7.5$ (m, 8H aromatic). ${ }^{13} \mathrm{C}-\mathrm{NMR}(125$

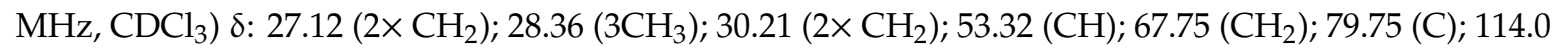
(CHAr); 116.43 (d, J = 31.25 Hz, CHAr); 117.40 (d, J = 26.25 Hz, CHAr); 122.36 (CHAr); 123.27 (C); 125.94 (CHAr); 127.55 (CHAr); 130.52 (CHAr); 130.84 (d, J = 11.25 Hz, CHAr); 138.20 (d, J = 20 Hz, C); $153.69(\mathrm{C}) ; 154.51(\mathrm{C}) ; 161.41(\mathrm{~d}, J=281.25 \mathrm{~Hz}, \mathrm{C}) ; 166.60(\mathrm{C})$. ESI $(\mathrm{m} / \mathrm{z})$ : calcd for $\mathrm{C}_{24} \mathrm{H}_{28} \mathrm{ClFN}_{2} \mathrm{O}_{4} 462.2$, found $463.0[\mathrm{M}+1]$; IR cm $\mathrm{cm}^{-1}: 1727.5$ (CO carbamate); 1693.33 (CO, amide).

\subsubsection{General Procedure for Deprotection: Synthesis of $\mathbf{6 a}-\mathbf{b}$}

One equiv of compound 5 was dissolved in $15 \mathrm{~mL}$ of $\mathrm{CH}_{2} \mathrm{Cl}_{2}$, and 13 equiv of trifluoroacetic acid were added. After $2 \mathrm{~h}$ of stirring at room temperature, the reaction mixture was concentrated under vacuum. The residue was dissolved in $5 \mathrm{~mL}$ of ethyl acetate then neutralized with $\mathrm{NaHCO}_{3}(5 \%)$. The aqueous layer was extracted with ethyl acetate $(4 \times 5 \mathrm{~mL})$. The combined organic phases were dried over $\mathrm{MgSO}_{4}$, filtered and concentrated under reduced pressure. The crude product was purified by crystallisation (ether petroleum/ethyl acetate (8:2)).

2-Phenoxy-N-Phenyl-N-(piperidin-4-yl) acetamide (6a). Following the general procedure, $3.06 \mathrm{~g}(7.48 \mathrm{mmol})$ of compound 5 a were dissolved in $15 \mathrm{~mL}$ of $\mathrm{CH}_{2} \mathrm{Cl}_{2}$, then $7.49 \mathrm{~mL}$ (97.24 mmol) of trifluoroacetic acid were added to produce compound $6 \mathrm{a}(1.15 \mathrm{~g}, 50 \%) ;$ m.p.: $59{ }^{\circ} \mathrm{C}$. ${ }^{1} \mathrm{H}-\mathrm{NMR}\left(\mathrm{CDCl}_{3}, 600 \mathrm{MHz}\right): 1.5$ $\left(\mathrm{m}, 2 \mathrm{H}, \mathrm{CH}_{2}\right) ; 1.9\left(\mathrm{~m}, 2 \mathrm{H}, \mathrm{CH}_{2}\right) ; 2.7\left(\mathrm{~m}, 2 \mathrm{H}, \mathrm{CH}_{2}\right) ; 3.4\left(\mathrm{~m}, 2 \mathrm{H}, \mathrm{CH}_{2}\right) ; 3.4($ broad, $1 \mathrm{H}, \mathrm{NH}) ; 4.6(\mathrm{~s}, 2 \mathrm{H}$, $\left.\mathrm{O}-\mathrm{CH}_{2}\right) ; 4.75(\mathrm{~m}, 1 \mathrm{H}, \mathrm{CH}), 6.5-7.7$ (m, 10H aromatic). ${ }^{13} \mathrm{C}-\mathrm{NMR}\left(150 \mathrm{MHz}, \mathrm{CDCl}_{3}\right) \delta: 30\left(2 \times \mathrm{CH}_{2}\right)$; $45.06\left(2 \times \mathrm{CH}_{2}\right) ; 52.15(\mathrm{CH}) ; 66.74\left(\mathrm{CH}_{2}\right) ; 114.76$ (2× CHAr); 121.53 (CHAr); 129.17 (CHAr); 129.46 (2× CHAr); 129.50 (CHAr); 130.00 (2× CHAr); 130.17 (CHAr); 136.63 (C); 158.07 (C); 167.48 (C). ESI $(\mathrm{m} / \mathrm{z})$ : calcd for $\mathrm{C}_{19} \mathrm{H}_{22} \mathrm{~N}_{2} \mathrm{O}_{2} 310.2$, found 311.0 [M + 1]; IR cm ${ }^{-1}: 3443(\mathrm{NH}), 1691.33(\mathrm{CO})$.

N-(3-Fluorophenyl)-2-phenoxy-N-(piperidin-4-yl) acetamide (6b). Following the general procedure, $4.65 \mathrm{~g}$ (10.87 mmol) of compound $5 \mathbf{b}$ were dissolved in $15 \mathrm{~mL}$ of $\mathrm{CH}_{2} \mathrm{Cl}_{2}, 10.81 \mathrm{~mL}(141.31 \mathrm{mmol})$ of trifluoroacetique acid were added. (2.5 g, 70\%); m.p.: $200{ }^{\circ} \mathrm{C} ;{ }^{1} \mathrm{H}-\mathrm{NMR}\left(\mathrm{CDCl}_{3}, 500 \mathrm{MHz}\right): 1.3$ (m, $\left.2 \mathrm{H}, \mathrm{CH}_{2}\right) ; 1.80\left(\mathrm{~m}, 2 \mathrm{H}, \mathrm{CH}_{2}\right) ; 2.85\left(\mathrm{~m}, 2 \mathrm{H}, \mathrm{CH}_{2}\right) ; 3.7$ (broad, $\left.1 \mathrm{H}, \mathrm{NH}\right) ; 4.06\left(\mathrm{~m}, 2 \mathrm{H}, \mathrm{CH}_{2}\right) ; 4.31(\mathrm{~m}, 2 \mathrm{H}$, $\left.\mathrm{CH}_{2}\right) ; 4.67(\mathrm{~m}, 1 \mathrm{H}, \mathrm{CH}) 6.4-7.5\left(\mathrm{~m}, 9 \mathrm{H}\right.$ aromatic). ${ }^{13} \mathrm{C}-\mathrm{NMR}\left(125 \mathrm{MHz}, \mathrm{CDCl}_{3}\right) \delta: 27.14\left(2 \times \mathrm{CH}_{2}\right) ; 43.99$ $\left(2 \times \mathrm{CH}_{2}\right) ; 51.11(\mathrm{CH}) ; 66.69\left(\mathrm{CH}_{2}\right) ; 114.74(2 \times \mathrm{CHAr}) ; 117.34(\mathrm{~d}, \mathrm{~J}=50.53 \mathrm{~Hz}, \mathrm{CHAr}) ; 121.97$ (CHAr); 129.68 (2× CHAr); 129.86 (CHAr); 131.71 (CHAr); 138.23 (C); 153.69 (C); 164.11-161.27 (C); 168.211 (C). ESI $(m / z)$ : calcd for $\mathrm{C}_{19} \mathrm{H}_{21} \mathrm{FN}_{2} \mathrm{O}_{2}$ 328.2; found $329.166[\mathrm{M}+1]$; IR cm ${ }^{-1}$ : $3445(\mathrm{NH}), 1693.01$ (CO).

2-(2-Chlorophenoxy)-N-Phenyl-N-(piperidin-4-yl) acetamide (6c). Compound 9 (3.90 g, $8.78 \mathrm{mmol})$ was dissolved in $15 \mathrm{~mL}$ of $\mathrm{CH}_{2} \mathrm{Cl}_{2}$, then $8.73 \mathrm{~mL}(114.14 \mathrm{mmol})$ of trifluoroacetic acid were added, to give 
6c $\left(3.02 \mathrm{~g}\right.$, 95\%); m.p.: $161{ }^{\circ} \mathrm{C} ;{ }^{1} \mathrm{H}-\mathrm{NMR}\left(\mathrm{CDCl}_{3}, 600 \mathrm{MHz}\right): 1.70\left(\mathrm{~m}, 2 \mathrm{H}, \mathrm{CH}_{2}\right) ; 1.93$ (broad, $\left.1 \mathrm{H}, \mathrm{NH}\right)$; $2.06\left(\mathrm{~m}, 2 \mathrm{H}, \mathrm{CH}_{2}\right) ; 2.97\left(\mathrm{~m}, 2 \mathrm{H}, \mathrm{CH}_{2}\right) ; 3.38\left(\mathrm{~m}, 2 \mathrm{H}, \mathrm{CH}_{2}\right) ; 4.37\left(\mathrm{~s}, 2 \mathrm{H}, \mathrm{CH}_{2}\right) ; 4.77(\mathrm{~m}, 1 \mathrm{H}, \mathrm{CH}) ; 6.5-7.5(\mathrm{~m}$, 9H Ar). ${ }^{13} \mathrm{C}-\mathrm{NMR}\left(150 \mathrm{MHz}, \mathrm{CDCl}_{3}\right)$ : $27.12\left(2 \times \mathrm{CH}_{2}\right) ; 43.55\left(2 \times \mathrm{CH}_{2}\right) ; 50.68(\mathrm{CH}) ; 67.53\left(\mathrm{CH}_{2}\right) ; 114.01$ (2× CHAr); 122.27 (CHAr); 123.27 (C); 127.55 (CHAr); 129.55(2× CHAr); 129.84 (CHAr); 130.24 (CHAr); 130.55 (CHAr); 135.76 (C); 153.67 (C); 167.27 (C). ESI (m/z): calcd for $\mathrm{C}_{19} \mathrm{H}_{21} \mathrm{ClN}_{2} \mathrm{O}_{2} 344.1$; found 345.13 $[\mathrm{M}+1] ; \mathrm{IR} \mathrm{cm}^{-1}: 3445(\mathrm{NH}), 1691.33(\mathrm{CO})$.

2-(2-Chlorophenoxy)-N-(3-fluorophenyl)-N-(piperidin-4-yl) acetamide (6d). Following the general procedure, $1.99 \mathrm{~g}(4.327 \mathrm{mmol})$ of compound 9 were dissolved in $15 \mathrm{~mL}$ of $\mathrm{CH}_{2} \mathrm{Cl}_{2}$, and $4.30 \mathrm{~mL}$ ( $\left.56.25 \mathrm{mmol}\right)$ of trifluoroacetic acid were added to afford $6 \mathrm{~d}\left(2.4 \mathrm{~g} \mathrm{60 \% );} \mathrm{m.p.:} 140^{\circ} \mathrm{C} ;{ }^{1} \mathrm{H}-\mathrm{NMR}\left(\mathrm{CDCl}_{3}, 600 \mathrm{MHz}\right): 1.40\right.$ $\left(\mathrm{m}, 2 \mathrm{H}, \mathrm{CH}_{2}\right) ; 2.06\left(\mathrm{~m}, 2 \mathrm{H}, \mathrm{CH}_{2}\right) ; 2.7$ (broad band, $\left.1 \mathrm{H}, \mathrm{NH}\right) 2.97\left(\mathrm{~m}, 2 \mathrm{H}, \mathrm{CH}_{2}\right) ; 3.2\left(\mathrm{~m}, 2 \mathrm{H}, \mathrm{CH}_{2}\right) ; 4.37$ (s, $\left.2 \mathrm{H}, \mathrm{CH}_{2}\right) ; 4.77(\mathrm{~m}, 1 \mathrm{H}, \mathrm{CH}) ; 6.5-7.5\left(\mathrm{~m}, 8 \mathrm{H}\right.$ aromatic). ${ }^{13} \mathrm{C}-\mathrm{NMR}\left(150 \mathrm{MHz}, \mathrm{CDCl}_{3}\right) \delta: 30.9\left(2 \times \mathrm{CH}_{2}\right)$; $45.7\left(2 \times \mathrm{CH}_{2}\right) ; 53.11(\mathrm{CH}) ; 67.79\left(\mathrm{CH}_{2}\right) ; 114.05(\mathrm{CHAr}) ; 116.55(\mathrm{~d}, J=24.9 \mathrm{~Hz}, \mathrm{CHAr}) ; 117.74(\mathrm{~d}$, $J=106.5 \mathrm{~Hz}, \mathrm{CHAr}) ; 122.447$ (CHAr); 123.27 (CHAr); 126.068 (d, $J=3.75 \mathrm{~Hz}, \mathrm{CHAr}) ; 127.673$ (CHAr); 130.619 (CHAr); 131.958 (d, J = $10.95 \mathrm{~Hz}, \mathrm{CHAr}$ ); 138.292 (C); 153.780 (C); 161.963 (d, J = 298.5 Hz, C); $166.60(\mathrm{C})$. ESI $(\mathrm{m} / \mathrm{z})$ : calcd for $\mathrm{C}_{19} \mathrm{H}_{20} \mathrm{ClFN}_{2} \mathrm{O}_{2} 362.1$; found $363.12[\mathrm{M}+1]$; $\mathrm{IR} \mathrm{cm}^{-1}: 3445(\mathrm{NH})$, $1691.33(\mathrm{CO})$.

\subsubsection{General Procedure for Synthesis of Target Compounds A}

A solution of benzaldehyde derivatives (1 equiv) in 1,2-dichloroethane containing compound 6 (1 equiv), sodium triacetoxyborohydride (1.5 equiv) and acetic acid (1.5 equiv) was stirred for $24 \mathrm{~h}$ at $20^{\circ} \mathrm{C} .1 \mathrm{~N} \mathrm{NaOH}(15 \mathrm{~mL})$ and $15 \mathrm{~mL}$ of ethyl acetate were added. The phases were separated and the aqueous layer was extracted with ethyl acetate $(3 \times 15 \mathrm{~mL})$. The combined organic layers were dried over $\mathrm{MgSO}_{4}$, filtered and concentrated under reduced pressure. The residue was purified by chromatography on silica gel (petroleum ether/EtOAc (8:2)).

$N$-(1-Benzylpiperidin-4-yl)-2-phenoxy-N-phenylacetamide (12a). Following the general procedure for reductive amination, using benzaldehyde derivative $\mathbf{1 1}\left(\mathrm{R}_{3}=\mathrm{H}\right)(34 \mathrm{mg}, 0.322 \mathrm{mmol})$; compound $\mathbf{6 a}$ (100 mg, $0.322 \mathrm{mmol})$; sodium triacetoxyborohydride $(102 \mathrm{mg}, 0.4838 \mathrm{mmol})$ and acetic acid $(29 \mathrm{mg}$, $0.4838 \mathrm{mmol})$ in 1,2-dichloroethane (5 mL) give compound 12a $(0.1291 \mathrm{~g}, 52 \%)$; m.p. $89^{\circ} \mathrm{C} .{ }^{1} \mathrm{H}-\mathrm{NMR}$ $\left(\mathrm{CDCl}_{3}, 600 \mathrm{MHz}\right): 1.32\left(\mathrm{~m}, 2 \mathrm{H}, \mathrm{CH}_{2}\right) ; 1.74\left(\mathrm{~m}, 2 \mathrm{H}, \mathrm{CH}_{2}\right) ; 2.06\left(\mathrm{~m}, 2 \mathrm{H}, \mathrm{CH}_{2}\right) ; 2.83\left(\mathrm{~m}, 2 \mathrm{H}, \mathrm{CH}_{2}\right) ; 3.42$ (s, 2H, $\left.\mathrm{CH}_{2}\right) ; 4.15\left(\mathrm{~s}, 2 \mathrm{H}, \mathrm{CH}_{2}\right) ; 4.62(\mathrm{~m}, \mathrm{H}, \mathrm{CH}) ; 6.68-7.38$ (m, $15 \mathrm{H}$ aromatic); ${ }^{13} \mathrm{C}-\mathrm{NMR}(150 \mathrm{MHz}$, $\left.\mathrm{CDCl}_{3}\right)$ 8: $32.17(2 \times \mathrm{CH} 2) ; 43.72\left(2 \times \mathrm{CH}_{2}\right) ; 52.84(\mathrm{CH}) ; 62.89\left(\mathrm{CH}_{2}\right) ; 66.73\left(\mathrm{CH}_{2}\right) ; 114.74(4 \times \mathrm{CHAr}) ;$ 121.32 (CHAr); 128.25 (CHAr); 129.08 (CHAr); 129.34 (4× CHAr); 129.68 (2× CHAr); 130.14 (2× CHAr); 135.30 (C) 136.69 (C); 158.14 (C); 167.25 (C). ESI (m/z): calcd for $\mathrm{C}_{26} \mathrm{H}_{28} \mathrm{~N}_{2} \mathrm{O}_{2} 400.02$; found 401.22 $[\mathrm{M}+1] ; \mathrm{IR} \mathrm{cm}^{-1}: 1680(\mathrm{CO})$.

$\mathrm{N}$-(1-Benzylpiperidin-4-yl)-N-(3-fluorophenyl)-2-phenoxyacetamide (12b). Following the general procedure, benzaldehyde derivative $11\left(\mathrm{R}_{3}=\mathrm{H}(\mathrm{o})\right)(48.4 \mathrm{mg}, 0.457 \mathrm{mmol})$; compound $6 \mathbf{b}(150 \mathrm{mg}, 0.457 \mathrm{mmol})$; sodium triacetoxyborohydride $(145.3 \mathrm{mg}, 0.6855 \mathrm{mmol})$ and acetic acid $(41.6 \mathrm{mg}, 0.6855 \mathrm{mmol})$ in 1.2-dichloroethane $(5 \mathrm{~mL})$ was stirred for $24 \mathrm{~h}$ at $20{ }^{\circ} \mathrm{C}$ to furnish $12 \mathrm{~b}(0.103 \mathrm{~g}, 54 \%)$; m.p.: $90{ }^{\circ} \mathrm{C}$. ${ }^{1} \mathrm{H}-\mathrm{NMR}\left(\mathrm{CDCl}_{3}, 500 \mathrm{MHz}\right): 1.36\left(\mathrm{~m}, 2 \mathrm{H}, \mathrm{CH}_{2}\right) ; 1.83\left(\mathrm{~m}, 2 \mathrm{H}, \mathrm{CH}_{2}\right) ; 2.15\left(\mathrm{~m}, 2 \mathrm{H}, \mathrm{CH}_{2}\right) ; 2.94\left(\mathrm{~m}, 2 \mathrm{H}, \mathrm{CH}_{2}\right)$; 3.50 (s, 2H, $\mathrm{CH}_{2}$ ); 4.30 (s, 2H, $\left.\mathrm{CH}_{2}\right) ; 4.67(\mathrm{~m}, \mathrm{H}, \mathrm{CH}) ; 6.78-7.47$ (m, $14 \mathrm{H}$ aromatic). ${ }^{13} \mathrm{C}-\mathrm{NMR}(125 \mathrm{MHz}$, $\left.\mathrm{CDCl}_{3}\right)$ 8: $30.26(2 \times \mathrm{CH} 2) ; 43.72\left(2 \times \mathrm{CH}_{2}\right) ; 52.84(\mathrm{CH}) ; 62.80\left(\mathrm{CH}_{2}\right) ; 66.81\left(\mathrm{CH}_{2}\right) ; 114.73(4 \times \mathrm{CHAr}) ;$ 117.50 (d, J = $22 \mathrm{~Hz}, \mathrm{CHAr}) ; 121.47$ (2× CHAr); 126.03 (CHAr); 127.16 (C); 128.24 (2× CHAr); 129.16 (CHAr); 129.40 (2× CHAr); 130.66 (CHAr); 138.67 (C); 157.99 (C); 161.59 (d, J = 251 Hz, C); 167.06 (C). ESI $(m / z)$ : calcd for $\mathrm{C}_{26} \mathrm{H}_{27} \mathrm{FN}_{2} \mathrm{O}_{2}$ 418.2; found $419.21[\mathrm{M}+1]$; IR cm ${ }^{-1}: 1687$.

2-(2-Chlorophenoxy)-N-(1-benzylpiperidin-4-yl)-N-phenylacetamide (12c). Following the general procedure, benzaldehyde derivative $11\left(\mathrm{R}_{3}=\mathrm{H}\right)(46.2 \mathrm{mg}, 0.435 \mathrm{mmol})$; compound $6 \mathrm{c}(150 \mathrm{mg}, 0.435 \mathrm{mmol})$; sodium triacetoxyborohydride $(138.5 \mathrm{mg}, 0.6538 \mathrm{mmol})$ and acetic acid $(39.5 \mathrm{mg}, 0.6538 \mathrm{mmol})$ in 1.2-dichloroethane $(5 \mathrm{~mL})$ was stirred for $24 \mathrm{~h}$ at $20{ }^{\circ} \mathrm{C}$ to afford $12 \mathrm{c}(0.0946 \mathrm{~g}, 50 \%)$; m.p.: $83{ }^{\circ} \mathrm{C}$; 
${ }^{1} \mathrm{H}-\mathrm{NMR}\left(\mathrm{CDCl}_{3}, 400 \mathrm{MHz}\right): 1.47\left(\mathrm{~m}, 2 \mathrm{H}, \mathrm{CH}_{2}\right) ; 1.84\left(\mathrm{~m}, 2 \mathrm{H}, \mathrm{CH}_{2}\right) ; 2.14\left(\mathrm{~m}, 2 \mathrm{H}, \mathrm{CH}_{2}\right) ; 2.94(\mathrm{~m}, 2 \mathrm{H}$, $\left.\mathrm{CH}_{2}\right) ; 3.48\left(\mathrm{~s}, 2 \mathrm{H}, \mathrm{CH}_{2}\right) ; 4.35\left(\mathrm{~s}, 2 \mathrm{H}, \mathrm{CH}_{2}\right) ; 4.64(\mathrm{~m}, \mathrm{H}, \mathrm{CH}) ; 6.73-7.47$ (m, $14 \mathrm{H}$ aromatic). ${ }^{13} \mathrm{C}-\mathrm{NMR}$ $\left(100 \mathrm{MHz}, \mathrm{CDCl}_{3}\right)$ 8: $30.23(2 \times \mathrm{CH} 2) ; 43.37\left(2 \times \mathrm{CH}_{2}\right) ; 52.88(\mathrm{CH}) ; 62.90\left(\mathrm{CH}_{2}\right) ; 67.66\left(\mathrm{CH}_{2}\right) ; 114.01$

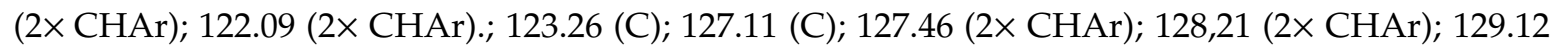
(CHAr); 129.71 (2× CHAr); 130.18 (2× CHAr); 130.41 (CHAr); 136.99 (C); 153.94 (C); 166.67 (C). ESI (m/z): calcd for $\mathrm{C}_{26} \mathrm{H}_{27} \mathrm{ClN}_{2} \mathrm{O}_{2} 434.2$; found 435.18 [M + 1]; $\mathrm{IR} \mathrm{cm}^{-1}$ : 1683 (CO).

2-(2-Chlorophenoxy)-N-(1-benzylpiperidin-4-yl)-N-(3-fluorophenyl) acetamide (12d). Following the general procedure, benzaldehyde derivatives $11\left(\mathrm{R}_{3}=\mathrm{H}(\mathrm{o})\right)(43.91 \mathrm{mg}, 0.4142 \mathrm{mmol})$; compound $\mathbf{6 d}$ (150, $0.4142 \mathrm{mmol})$; sodium triacetoxyborohydride $(131.6 \mathrm{mg}, 0.6213 \mathrm{mmol})$ and acetic acid $(37.3 \mathrm{mg}$, $0.6213 \mathrm{mmol})$ in 1,2-dichloroethane $(5 \mathrm{~mL})$ was stirred for $24 \mathrm{~h}$ at $20^{\circ} \mathrm{C}$, giving $12 \mathrm{~d}(0.0936 \mathrm{~g}, 54 \%)$; m.p.: $73{ }^{\circ} \mathrm{C} .{ }^{1} \mathrm{H}-\mathrm{NMR}\left(\mathrm{CDCl}_{3}, 600 \mathrm{MHz}\right): 1.25\left(\mathrm{~m}, 2 \mathrm{H}, \mathrm{CH}_{2}\right) ; 1.43\left(\mathrm{~m}, 2 \mathrm{H}, \mathrm{CH}_{2}\right) ; 1.78\left(\mathrm{~m}, 2 \mathrm{H}, \mathrm{CH}_{2}\right)$; $2.14\left(\mathrm{~m}, 2 \mathrm{H}, \mathrm{CH}_{2}\right) ; 2.92\left(\mathrm{~s}, 2 \mathrm{H}, \mathrm{CH}_{2}\right) ; 3.49\left(\mathrm{~s}, 2 \mathrm{H}, \mathrm{CH}_{2}\right) ; 4.36\left(\mathrm{~s}, 2 \mathrm{H}, \mathrm{CH}_{2}\right) ; 4.63(\mathrm{~m}, \mathrm{H}, \mathrm{CH}) ; 6.73-7.47$ (m, 13H aromatic). ${ }^{13} \mathrm{C}-\mathrm{NMR}\left(150 \mathrm{MHz}, \mathrm{CDCl}_{3}\right) \delta: 30.12\left(2 \times \mathrm{CH}_{2}\right) ; 43.37\left(2 \times \mathrm{CH}_{2}\right) ; 52.82(\mathrm{CH}) ; 62.90$ $\left(\mathrm{CH}_{2}\right) ; 67.77\left(\mathrm{CH}_{2}\right) ; 114.03$ (2× CHAr); $116.50(\mathrm{CHAr}) ; 116.67(\mathrm{C}) ; 117.63(\mathrm{~d}, J=21.36 \mathrm{~Hz}, \mathrm{CHAr}) ; 122.39$ (2× CHAr); 123.31 (C); 126.11 (d, J = 2.51 Hz, CHAr); 127.65 (CHAr); 128.43 (CHAr); 129.41 (CHAr); 130.60 (2× CHAr); 130.93 (d, J = 8.79 Hz, CHAr); 138.36 (C); 153.81 (C); 161.95 (d, J = 250.14 Hz, C); 166.67 (C). ESI $(m / z)$ : calcd for $\mathrm{C}_{26} \mathrm{H}_{26} \mathrm{ClFN}_{2} \mathrm{O}_{2}$ 452.2; found 453.18 [M + 1]; IR cm ${ }^{-1}: 1689$ (CO).

$N-(1-(2-B r o m o b e n z y l)$ piperidin-4-yl)-2-phenoxy-N-phenylacetamide (13a). Following the general procedure for reductive amination using benzaldehyde derivative $11\left(\mathrm{R}_{3}=\mathrm{Br}(o)\right)(75.3 \mathrm{mg}, 0.410 \mathrm{mmol})$; compound $6 \mathbf{6}(127 \mathrm{mg}, 0.410 \mathrm{mmol})$; sodium triacetoxyborohydride $(130.15 \mathrm{mg}, 0.615 \mathrm{mmol})$ and acetic acid (36.9 mg, $0.615 \mathrm{mmol})$ ) in 1,2-dichloroethane ( $5 \mathrm{~mL})$ to give compound 13a $(0.119 \mathrm{~g}, 60 \%)$; m.p. $66^{\circ} \mathrm{C} .{ }^{1} \mathrm{H}-\mathrm{NMR}\left(\mathrm{CDCl}_{3}, 600 \mathrm{MHz}\right): 1.44\left(\mathrm{~m}, 2 \mathrm{H}, \mathrm{CH}_{2}\right) ; 1.64\left(\mathrm{~m}, 2 \mathrm{H}, \mathrm{CH}_{2}\right) ; 2.25\left(\mathrm{~m}, 2 \mathrm{H}, \mathrm{CH}_{2}\right) ; 2.90(\mathrm{~m}$, $\left.2 \mathrm{H}, \mathrm{CH}_{2}\right) ; 3.53\left(\mathrm{~s}, 2 \mathrm{H}, \mathrm{CH}_{2}\right) ; 4.23\left(\mathrm{~s}, 2 \mathrm{H}, \mathrm{CH}_{2}\right) ; 4.70(\mathrm{~m}, \mathrm{H}, \mathrm{CH}) ; 6.73-7.47$ (m, $14 \mathrm{H}$ aromatic). ${ }^{13} \mathrm{C}-\mathrm{NMR}$ $\left(150 \mathrm{MHz}, \mathrm{CDCl}_{3}\right) \delta: 30.50\left(2 \times \mathrm{CH}_{2}\right) ; 53.07(\mathrm{CH}) ; 53.13\left(2 \times \mathrm{CH}_{2}\right) ; 61.77\left(\mathrm{CH}_{2}\right) ; 66.77\left(\mathrm{CH}_{2}\right) ; 114.80$ (2× CHAr); 121.42 (CHAr); 124.69 (C); 127.27 (CHAr); 128.44 (CHAr); 129.20 (CHAr); 129.46 (2× CHAr); 129.82 (2× CHAr); 130.24 (2× CHAr); 130.64 (CHAr); 132.82 (CHAr); 137.12 (C); 137.21 (C); 158.19 (C); 167.33 (C). ESI ( $m / z)$ : calcd for $\mathrm{C}_{26} \mathrm{H}_{27} \mathrm{BrN}_{2} \mathrm{O}_{2} 478.1$; found 479.13 [M + 1]; $\mathrm{IR} \mathrm{cm}^{-1}$ : 1678 (CO).

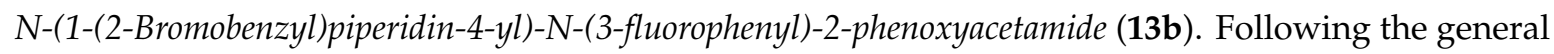
procedure, benzaldehyde derivatives $11\left(\mathrm{R}_{3}=\mathrm{Br}(o)\right)(84.5 \mathrm{mg} ; 0.457 \mathrm{mmol})$; compound $6 \mathbf{b}(150 \mathrm{mg}$, $0.457 \mathrm{mmol})$; sodium triacetoxyborohydride $(142.29 \mathrm{mg}, 0.685 \mathrm{mmol})$ and acetic acid $(41.16 \mathrm{mg}$, $0.685 \mathrm{mmol})$ in 1,2-dichloroethane $(5 \mathrm{~mL})$ was stirred for $24 \mathrm{~h}$ at $20^{\circ} \mathrm{C}$. Yield of $13 \mathrm{~b}: 0.176 \mathrm{~g}(58 \%)$; IR cm ${ }^{-1}$ : 1687; MS: 469.14 [M + 1]; m.p.: $55^{\circ} \mathrm{C} ; \mathrm{H}^{1}-\mathrm{NMR}\left(\mathrm{CDCl}_{3}, 500 \mathrm{MHz}\right): 1.36\left(\mathrm{~m}, 2 \mathrm{H}, \mathrm{CH}_{2}\right)$; $1.83\left(\mathrm{~m}, 2 \mathrm{H}, \mathrm{CH}_{2}\right) ; 2.15\left(\mathrm{~m}, 2 \mathrm{H}, \mathrm{CH}_{2}\right) ; 2.94\left(\mathrm{~m}, 2 \mathrm{H}, \mathrm{CH}_{2}\right) ; 3.50\left(\mathrm{~s}, 2 \mathrm{H}, \mathrm{CH}_{2}\right) ; 4.30\left(\mathrm{~s}, 2 \mathrm{H}, \mathrm{CH}_{2}\right) ; 4.67$ (m, H, CH); 6.78-7.47 (m, 13H aromatic). ${ }^{13} \mathrm{C}-\mathrm{NMR}\left(125 \mathrm{MHz}, \mathrm{CDCl}_{3}\right) \delta: 30.26\left(2 \times \mathrm{CH}_{2}\right) ; 42.89(2 \times$ $\left.\mathrm{CH}_{2}\right) ; 52.98(\mathrm{CH}) ; 61.65\left(\mathrm{CH}_{2}\right) ; 66.88\left(\mathrm{CH}_{2}\right) ; 114.81(4 \times \mathrm{CHAr}) ; 116.42(\mathrm{~d}, J=20 \mathrm{~Hz}, \mathrm{CHAr}) ; 117.52(\mathrm{~d}$, $J=20 \mathrm{~Hz}, \mathrm{CHAr}$ ); 121.47 (2× CHAr); 126.06 (CHAr); 128.56 (C); 129.53 (4× CHAr); 130.22 (d, J = 11,25 $\mathrm{Hz}, \mathrm{C}) ; 132.90$ (CHAr); 138.73 (C); 158.05 (C); 161.59 (d, J = 247,5 Hz, C); 167.23 (C). ESI ( $\mathrm{m} / \mathrm{z}$ ): calcd for $\mathrm{C}_{26} \mathrm{H}_{26} \mathrm{BrFN}_{2} \mathrm{O}_{2}$ 496.1; found 497.14 [M + 1]. IR cm ${ }^{-1}: 1687$ (CO).

$N-(1-(2-B r o m o b e n z y l) p i p e r i d i n-4-y l)-2-(2-c h l o r o p h e n o x y)-N-p h e n y l a c e t a m i d e(13 \mathbf{c})$. Following the general procedure, benzaldehyde derivatives $11\left(\mathrm{R}_{3}=\mathrm{Br}(\mathrm{o})\right)(80.5 \mathrm{mg} ; 0.435 \mathrm{mmol})$; compound $6 \mathrm{c}(150 \mathrm{mg}$, $0.435 \mathrm{mmol})$; sodium triacetoxyborohydride $(138 \mathrm{mg}, 0.653 \mathrm{mmol})$ and acetic acid $(39.2 \mathrm{mg}, 0.653 \mathrm{mmol})$ in 1,2-dichloroethane $(5 \mathrm{~mL})$ was stirred for $24 \mathrm{~h}$ at $20{ }^{\circ} \mathrm{C}$ to give $13 \mathrm{c}(0.122 \mathrm{~g}, 55 \%)$; m.p.: $64{ }^{\circ} \mathrm{C}$. ${ }^{1} \mathrm{H}-\mathrm{NMR}\left(\mathrm{CDCl}_{3}, 400 \mathrm{MHz}\right): 1.36\left(\mathrm{~m}, 2 \mathrm{H}, \mathrm{CH}_{2}\right) ; 1.86\left(\mathrm{~m}, 2 \mathrm{H}, \mathrm{CH}_{2}\right) ; 2.27\left(\mathrm{~m}, 2 \mathrm{H}, \mathrm{CH}_{2}\right) ; 2.94(\mathrm{~m}, 2 \mathrm{H}$, $\left.\mathrm{CH}_{2}\right) ; 3.57\left(\mathrm{~s}, 2 \mathrm{H}, \mathrm{CH}_{2}\right) ; 4.35\left(\mathrm{~s}, 2 \mathrm{H}, \mathrm{CH}_{2}\right) ; 4.742(\mathrm{~m}, \mathrm{H}, \mathrm{CH}) ; 6.73-747\left(\mathrm{~m}, 13 \mathrm{H}\right.$ aromatic). ${ }^{13} \mathrm{C}-\mathrm{NMR}$ $\left(100 \mathrm{MHz}, \mathrm{CDCl}_{3}\right)$ \&: $30.34\left(2 \times \mathrm{CH}_{2}\right) ; 42.98\left(2 \times \mathrm{CH}_{2}\right) ; 52.97(\mathrm{CH}) ; 61.63\left(\mathrm{CH}_{2}\right) ; 67.66\left(2 \mathrm{H}, \mathrm{CH}_{2}\right) ; 113.99$ (2× CHAr); 122.10 (CHAr); 123.35 (C); 124.62 (C); 127.21 (C); 127.47 (2× CHAr); 128.82 (2× CHAr); 129.74 (2× CHAr); 130.14 (CHAr); 130.42 (CHAr); 132.72 (2× CHAr); 136.91 (C); 153.93 (C); 166.70 (C). ESI $(m / z)$ : calcd for $\mathrm{C}_{26} \mathrm{H}_{6} \mathrm{BrClN}_{2} \mathrm{O}_{2}$ 512.1; found 513.09 [M + 1]; $\mathrm{IR} \mathrm{cm}^{-1}: 1651$ (CO). 
$N-(1-(2-B r o m o b e n z y l)$ piperidin-yl)-2-(2-chlorophenoxy)-N-(3-fluorophenyl) acetamide (13d). Following the general procedure, benzaldehyde derivative $11\left(\mathrm{R}_{3}=\mathrm{Br}(o)\right)(76.63 \mathrm{mg}, 0.4142 \mathrm{mmol})$; compound $\mathbf{6 d}$ $(150 \mathrm{mg}, 0.4142 \mathrm{mmol})$; sodium triacetoxyborohydride $(131.6 \mathrm{mg}, 0.6213 \mathrm{mmol})$ and acetic acid $(37.3 \mathrm{mg}$, $0.6213 \mathrm{mmol})$ in 1,2-dichloroethane $(5 \mathrm{~mL})$ was stirred for $24 \mathrm{~h}$ at $20^{\circ} \mathrm{C}$ to furnish $13 \mathrm{~d}(0.1295 \mathrm{~g}, 59 \%)$; m.p.: $100{ }^{\circ} \mathrm{C} ;{ }^{1} \mathrm{H}-\mathrm{NMR}\left(\mathrm{CDCl}_{3}, 600 \mathrm{MHz}\right): 1.33\left(\mathrm{~m}, 2 \mathrm{H}, \mathrm{CH}_{2}\right) ; 1.80\left(\mathrm{~m}, 2 \mathrm{H}, \mathrm{CH}_{2}\right) ; 2.23\left(\mathrm{~m}, 2 \mathrm{H}, \mathrm{CH}_{2}\right)$; $2.92\left(\mathrm{~m}, 2 \mathrm{H}, \mathrm{CH}_{2}\right) ; 3.54\left(\mathrm{~s}, 2 \mathrm{H}, \mathrm{CH}_{2}\right) ; 4.37\left(\mathrm{~s}, 2 \mathrm{H}, \mathrm{CH}_{2}\right) ; 4.74(\mathrm{~m}, \mathrm{H}, \mathrm{CH}) ; 6.73-7.47$ (m, $12 \mathrm{H}$ aromatic). ${ }^{13} \mathrm{C}-\mathrm{NMR}\left(150 \mathrm{MHz}, \mathrm{CDCl}_{3}\right)$ 8: $30.45\left(2 \times \mathrm{CH}_{2}\right) ; 43.41\left(2 \times \mathrm{CH}_{2}\right) ; 53.04(\mathrm{CH}) ; 61.72\left(\mathrm{CH}_{2}\right) ; 67.74\left(\mathrm{CH}_{2}\right)$; 113.95 (2× CHAr); 116.50 (d, J = 21 Hz, CHAr); 117.78 (d, J = 21 Hz, CHAr); 122.38 (CHAr); 123.25 (C); 124.70 (C); 126.17 (CHAr); 127.32 (CHAr); 127.66 (CHAr); 128.51 (CHAr); 130.60 (CHAr); 130.92 (d, $J=9 \mathrm{~Hz}, \mathrm{CHAr}$ ); 132.86 (CHAr);138.60 (C); 138.51 (C); 153.78 (C); 162.10 (d, J = 249 Hz, C); 166.68 (C). ESI $(m / z)$ : calcd for $\mathrm{C}_{26} \mathrm{H}_{25} \mathrm{BrClFN}_{2} \mathrm{O}_{2}$ 530.1; found 531.08 [M + 1]; $\mathrm{IR} \mathrm{cm}^{-1}: 1689$ (CO).

$N$-(1-(2-Chlorobenzyl)piperidin-4-yl)-2-phenoxy-N-phenylacetamide (14a). Following the general procedure for reductive amination using benzaldehyde derivative $11\left(\mathrm{R}_{3}=\mathrm{Cl}(o)\right)(43.5 \mathrm{mg}, 0.4838 \mathrm{mmol})$; compound $6 \mathbf{a}(150 \mathrm{mg}, 0.4838 \mathrm{mmol})$; sodium triacetoxyborohydride $(153.8 \mathrm{mg}, 0.7253 \mathrm{mmol})$ and acetic acid $(43.5 \mathrm{mg}, 0.7253 \mathrm{mmol})$ in 1,2-dichloroethane $(5 \mathrm{~mL})$ gave title compound 14a $(0.109 \mathrm{~g}, 52 \%)$; m.p.: $69^{\circ} \mathrm{C} .{ }^{1} \mathrm{H}-\mathrm{NMR}\left(\mathrm{CDCl}_{3}, 500 \mathrm{MHz}\right): 1.47\left(\mathrm{~m}, 2 \mathrm{H}, \mathrm{CH}_{2}\right) ; 1.81\left(\mathrm{~m}, 2 \mathrm{H}, \mathrm{CH}_{2}\right) ; 2.28\left(\mathrm{~m}, 2 \mathrm{H}, \mathrm{CH}_{2}\right)$; $2.94\left(\mathrm{~m}, 2 \mathrm{H}, \mathrm{CH}_{2}\right) ; 3.59\left(\mathrm{~s}, 2 \mathrm{H}, \mathrm{CH}_{2}\right) ; 4.23\left(\mathrm{~s}, 2 \mathrm{H}, \mathrm{CH}_{2}\right) ; 4.67(\mathrm{~m}, \mathrm{H}, \mathrm{CH}) ; 6.73-7.47$ (m, 14H aromatic). ${ }^{13} \mathrm{C}-\mathrm{NMR}\left(125 \mathrm{MHz}, \mathrm{CDCl}_{3}\right)$ 8: $30.32\left(2 \times \mathrm{CH}_{2}\right) ; 42.30\left(2 \times \mathrm{CH}_{2}\right) ; 53.03\left(\mathrm{CH}_{2}\right) ; 66.82\left(\mathrm{CH}_{2}\right) ; 114.84$ (4× CHAr); 121.45 (2× CHAr); 126.73 (C); 129.25 (CHAr); 129.47 (4× CHAr); 129.58 (CHAr): 129.85 (CHAr); 130.20 (CHAr); 134.50 (C); 137.02 (C); 158.22 (C); 167.40 (C). ESI (m/z): calcd for $\mathrm{C}_{26} \mathrm{H}_{27} \mathrm{ClN}_{2} \mathrm{O}_{2}$ 434.2; found 435.18 [M + 1]; IR cm ${ }^{-1}: 1673$ (CO).

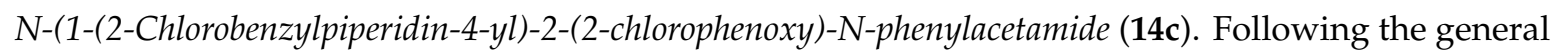
procedure, benzaldehyde derivative $11\left(\mathrm{R}_{3}=\mathrm{Cl}(o)\right)(61.02 \mathrm{mg} ; 0.4359 \mathrm{mmol})$; compound $6 \mathrm{c}(150 \mathrm{mg}$, $0.4359 \mathrm{mmol})$; sodium triacetoxyborohydride $(138.58 \mathrm{mg}, 0.6538 \mathrm{mmol})$ and acetic acid $(39.26 \mathrm{mg}$, $0.6538 \mathrm{mmol})$ in 1,2-dichloroethane $(5 \mathrm{~mL})$ was stirred for $24 \mathrm{~h}$ at $20^{\circ} \mathrm{C}$ to produce $14 \mathrm{c}(0.1326 \mathrm{~g}, 65 \%)$; m.p.: $55^{\circ} \mathrm{C} ;{ }^{1} \mathrm{H}-\mathrm{NMR}\left(\mathrm{CDCl}_{3}, 400 \mathrm{MHz}\right): 1.36\left(\mathrm{~m}, 2 \mathrm{H}, \mathrm{CH}_{2}\right) ; 1.75\left(\mathrm{~m}, 2 \mathrm{H}, \mathrm{CH}_{2}\right) ; 2.16\left(\mathrm{~m}, 2 \mathrm{H}, \mathrm{CH}_{2}\right)$; $2.84\left(\mathrm{~m}, 2 \mathrm{H}, \mathrm{CH}_{2}\right) ; 3.49\left(\mathrm{~s}, 2 \mathrm{H}, \mathrm{CH}_{2}\right) ; 4.25\left(\mathrm{~s}, 2 \mathrm{H}, \mathrm{CH}_{2}\right) ; 4.62(\mathrm{~m}, \mathrm{H}, \mathrm{CH}) ; 6.64-7.37$ (m, 13H aromatic). ${ }^{13} \mathrm{C}-\mathrm{NMR}\left(100 \mathrm{MHz}, \mathrm{CDCl}_{3}\right)$ 8: $30.38\left(2 \times \mathrm{CH}_{2}\right) ; 52.99(\mathrm{CH}) ; 53.03\left(2 \times \mathrm{CH}_{2}\right) ; 59.09\left(\mathrm{CH}_{2}\right) ; 67.64\left(\mathrm{CH}_{2}\right)$; 113.97 (2× CHAr); 122.10 (2× CHAr); 123.24 (C); 127.47 (2× CHAr); 129.15 (C); 129.35 (CHAr); 129.44 (C); 129.75 (2× CHAr); 130.15 (2× CHAr); 130.42 (2× CHAr); 140.41 (C); 153.92 (C); 166.69 (C). ESI (m/z): calcd for $\mathrm{C}_{26} \mathrm{H}_{26} \mathrm{Cl}_{2} \mathrm{~N}_{2} \mathrm{O}_{2}$ 468.1; found 469.14 [M + 1]. IR cm ${ }^{-1}$ : 1687 (CO).

$N$-(1-(2-Chlorobenzyl)piperidin-4-yl)-2-(2-chlorophenoxy)-N-(3-fluorophenyl) acetamide (14d). Following the general procedure, benzaldehyde derivative $\mathbf{1 1}\left(\mathrm{R}_{3}=\mathrm{Cl}(o)\right)(57.9 \mathrm{mg}, 0.4142 \mathrm{mmol})$; compound 6d (150 mg, $0.4142 \mathrm{mmol})$; sodium triacetoxyborohydride $(131.6 \mathrm{mg}, 0.6213 \mathrm{mmol})$ and acetic acid $(37.3 \mathrm{mg}, 0.6213 \mathrm{mmol})$ in 1,2-dichloroethane $(5 \mathrm{~mL})$ was stirred for $24 \mathrm{~h}$ at $20^{\circ} \mathrm{C}$ to give $14 \mathrm{~d}(0.11 \mathrm{~g}$, $55 \%)$; m.p.: $85^{\circ} \mathrm{C} ;{ }^{1} \mathrm{H}-\mathrm{NMR}\left(\mathrm{CDCl}_{3}, 600 \mathrm{MHz}\right): 1.44\left(\mathrm{~m}, 2 \mathrm{H}, \mathrm{CH}_{2}\right) ; 1.78\left(\mathrm{~m}, 2 \mathrm{H}, \mathrm{CH}_{2}\right) ; 2.22\left(\mathrm{~m}, 2 \mathrm{H}, \mathrm{CH}_{2}\right)$; $2.92\left(\mathrm{~m}, 2 \mathrm{H}, \mathrm{CH}_{2}\right) ; 3.56\left(\mathrm{~s}, 2 \mathrm{H}, \mathrm{CH}_{2}\right) ; 4.36\left(\mathrm{~s}, 2 \mathrm{H}, \mathrm{CH}_{2}\right) ; 4.64(\mathrm{~m}, \mathrm{H}, \mathrm{CH}) ; 6.73-7.37$ (m, 12H aromatic). ${ }^{13} \mathrm{C}-\mathrm{NMR}\left(150 \mathrm{MHz}, \mathrm{CDCl}_{3}\right)$ 8: $30.42\left(2 \times \mathrm{CH}_{2}\right) ; 53.04(\mathrm{CH}) ; 53.37\left(2 \times \mathrm{CH}_{2}\right) ; 59.17\left(\mathrm{CH}_{2}\right) ; 67.74\left(\mathrm{CH}_{2}\right)$; 113.95 (2× CHAr); 116.62 (d, J = 21 Hz, CHAr); 117.78 (d, J = $21 \mathrm{~Hz}, \mathrm{CHAr}) ; 122.36$ (CHAr); 123.25 (C); 126.16 (CHAr); 126.68 (CHAr); 127.66 (CHAr); 128.24 (CHAr); 129.55 (CHAr); 130.59 (CHAr); 130.91 (d, $J=10.5 \mathrm{~Hz}, \mathrm{CHAr}) ; 134.34$ (C); 136 (C); 138.44 (d, J = 7.5 Hz, C); 153.78 (C); 162.09 (d, J = $249 \mathrm{~Hz}, \mathrm{C})$; 166.62 (C). ESI ( $m / z)$ : calcd for $\mathrm{C}_{26} \mathrm{H}_{25} \mathrm{Cl}_{2} \mathrm{FN}_{2} \mathrm{O}_{2} 486.1$; found 487.13 [M + 1]; IR cm ${ }^{-1}$ : 1688 (CO).

$N-(1-(2.4-D i h y d r o x y b e n z y l)$ piperidin-4-yl)-2-phenoxy-N-phenylacetamide (15a). Following the general procedure for reductive amination using benzaldehyde derivative $\mathbf{1 1}\left(\mathrm{R}_{3}=\mathrm{OH}(o), \mathrm{OH}(p)\right)(66.86 \mathrm{mg}$, $0.4838 \mathrm{mmol})$; compound $6 \mathrm{a}(150 \mathrm{mg}, 0.4838 \mathrm{mmol})$; sodium triacetoxyborohydride $(153.8 \mathrm{mg}$, $0.725 \mathrm{mmol})$ and acetic acid (43 $\mathrm{mg}, 0.725 \mathrm{mmol})$ in 1,2-dichloroethane $(5 \mathrm{~mL})$ give compound $15 \mathrm{a}$ $\left(0.1233\right.$ g, 59\%); m.p. $68{ }^{\circ} \mathrm{C} .{ }^{1} \mathrm{H}-\mathrm{NMR}\left(\mathrm{CDCl}_{3}, 600 \mathrm{MHz}\right): 1.42\left(\mathrm{~m}, 2 \mathrm{H}, \mathrm{CH}_{2}\right) ; 2.23\left(\mathrm{~m}, 2 \mathrm{H}, \mathrm{CH}_{2}\right) ; 3.03(\mathrm{~m}$, $\left.2 \mathrm{H}, \mathrm{CH}_{2}\right) ; 3.16\left(\mathrm{~m}, 2 \mathrm{H}, \mathrm{CH}_{2}\right) ; 3.60\left(\mathrm{~s}, 2 \mathrm{H}, \mathrm{CH}_{2}\right) ; 4.23\left(\mathrm{~s}, 2 \mathrm{H}, \mathrm{CH}_{2}\right) ; 4.86(\mathrm{~m}, \mathrm{H}, \mathrm{CH}) ; 5.30(\mathrm{~s}, 2 \times \mathrm{OH})$; 
6.73-7.42 (m, 13HAr). ${ }^{13} \mathrm{C}-\mathrm{NMR}\left(150 \mathrm{MHz}, \mathrm{CDCl}_{3}\right)$ 8: $30.27\left(2 \times \mathrm{CH}_{2}\right) ; 43.66\left(2 \times \mathrm{CH}_{2}\right) ; 51.96\left(\mathrm{CH}_{2}\right)$; $52.80(\mathrm{CH}) ; 67.24\left(\mathrm{CH}_{2}\right) ; 114.57$ (CHAr); 114.79 (4× CHAr); 121.57 (CHAr); 129.52 (4× CHAr); 129.73 (CHAr); 129.98 (CHAr); 130.09 (CHAr); 136.57 (C); 156.45 (C); 156.66 (C); 157.51 (C); 158.10 (C); 166.78 (C). ESI ( $m / z)$ : calcd for $\mathrm{C}_{26} \mathrm{H}_{28} \mathrm{O}_{4} 432.2$; found 433.22 [M + 1]; IR cm ${ }^{-1}$ : 1661 (CO).

N-(-1(2-Hydroxy-6-methoxybenzyl)piperidin-4-yl)-2-phenoxy-N-phenylacetamide (16a). Following the general procedure reductive amination using benzaldehyde derivative $\mathbf{1 1}\left(\mathrm{R}_{3}=\mathrm{OMe}(o), \mathrm{OH}(o)\right)$ (73.55 mg, $0.4838 \mathrm{mmol})$; compound $6 \mathbf{6}(150 \mathrm{mg}, 0.4838 \mathrm{mmol})$; sodium triacetoxyborohydride (153.8 $\mathrm{mg}, 0.7253 \mathrm{mmol})$ and acetic acid $(43.5 \mathrm{mg}, 0.7253 \mathrm{mmol})$ in 1.2-dichloroethane $(5 \mathrm{~mL})$ give the title compound 16a $(0.114 \mathrm{~g}, 53 \%)$; mp $68^{\circ} \mathrm{C} .{ }^{1} \mathrm{H}-\mathrm{NMR}\left(\mathrm{CDCl}_{3}, 600 \mathrm{MHz}\right): 1.44\left(\mathrm{~m}, 2 \mathrm{H}, \mathrm{CH}_{2}\right) ; 1.87(\mathrm{~m}, 2 \mathrm{H}$, $\left.\mathrm{CH}_{2}\right) ; 2.25\left(\mathrm{~m}, 2 \mathrm{H}, \mathrm{CH}_{2}\right) ; 3.02\left(\mathrm{~m}, 2 \mathrm{H}, \mathrm{CH}_{2}\right) ; 3.75\left(\mathrm{~s}, 5 \mathrm{H}, \mathrm{CH}_{2}, \mathrm{CH}_{3}\right) ; 4.22\left(\mathrm{~s}, 2 \mathrm{H}, \mathrm{CH}_{2}\right) ; 4.62(\mathrm{~m}, \mathrm{H}, \mathrm{CH})$; 6.68-7.38 (m, 13HAr). ${ }^{13} \mathrm{C}-\mathrm{NMR}\left(150 \mathrm{MHz}, \mathrm{CDCl}_{3}\right)$ 8: $30.30\left(2 \times \mathrm{CH}_{2}\right) ; 43.72\left(2 \times \mathrm{CH}_{2}\right) ; 52.45\left(\mathrm{CH}_{2}\right)$; $52.62(\mathrm{CH}) ; 55.61\left(\mathrm{CH}_{3}\right) ; 66.68\left(\mathrm{CH}_{2}\right) ; 101.61$ (CHAr); 109.32 (C); 114.91 (2× CHAr); 121.49 (CHAr);

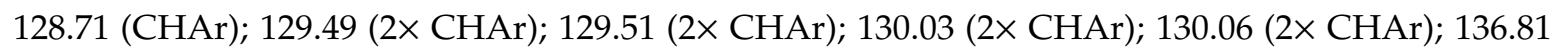
(C); $157.71(\mathrm{C}) ; 158.14(\mathrm{C}) ; 159.11(\mathrm{C}) ; 167.54(\mathrm{C})$. ESI (m/z): calcd for $\mathrm{C}_{27} \mathrm{H}_{30} \mathrm{~N}_{2} \mathrm{O}_{4} 446.2$; found 447.29 $[\mathrm{M}+1] ; \mathrm{IR} \mathrm{cm}^{-1}: 1678(\mathrm{CO})$.

N-(1-(Perfluorobenzyl)piperidin-4-yl)-2-phenoxy-N-phenylacetamide (17a). Following the general procedure, benzaldehyde derivative $11\left(\mathrm{R}_{3}=5 \times \mathrm{F}(0, \mathrm{~m}, \mathrm{p})\right)(94.87 \mathrm{mg} ; 0.483 \mathrm{mmol})$; compound $6 \mathrm{a}(150 \mathrm{mg}$, $0.483 \mathrm{mmol})$; sodium triacetoxyborohydride $(153 \mathrm{mg}, 0.7258 \mathrm{mmol})$ and acetic acid $(43 \mathrm{mg}, 0.7258 \mathrm{mmol})$ in 1,2-dichloroethane $(5 \mathrm{~mL})$ was stirred for $24 \mathrm{~h}$ at $20^{\circ} \mathrm{C}$ to afford $17 \mathrm{a}(0.118 \mathrm{~g}, 50 \%)$; m.p.: $104{ }^{\circ} \mathrm{C}$. ${ }^{1} \mathrm{H}-\mathrm{NMR}\left(\mathrm{CDCl}_{3}, 600 \mathrm{MHz}\right): 1.42\left(\mathrm{~m}, 2 \mathrm{H}, \mathrm{CH}_{2}\right) ; 1.79\left(\mathrm{~m}, 2 \mathrm{H}, \mathrm{CH}_{2}\right) ; 2.24\left(\mathrm{~m}, 2 \mathrm{H}, \mathrm{CH}_{2}\right) ; 2.88(\mathrm{~m}, 2 \mathrm{H}$, $\left.\mathrm{CH}_{2}\right) ; 3.65$ (s, 2H, $\left.\mathrm{CH}_{2}\right) ; 4.21$ (s, 2H, $\left.\mathrm{CH}_{2}\right) ; 4.60(\mathrm{~m}, \mathrm{H}, \mathrm{CH}) ; 6.73-7.42\left(\mathrm{~m}, 10 \mathrm{H}\right.$ aromatic). ${ }^{13} \mathrm{C}-\mathrm{NMR}$ $\left(150 \mathrm{MHz}, \mathrm{CDCl}_{3}\right) \delta: 30.27\left(2 \times \mathrm{CH}_{2}\right) ; 48.64\left(\mathrm{CH}_{2}\right) ; 52.18\left(2 \times \mathrm{CH}_{2}\right) ; 52.40(\mathrm{CH}) ; 66.77\left(\mathrm{CH}_{2}\right) ; 114.81$

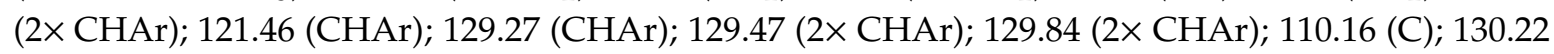
(2× CHAr); 136.56 (C); 136.88 (C); 138.16 (C); 144.42 (2× C); 146.42 (C); 158.15 (C); 167.36 (C). ESI (m/z): calcd for $\mathrm{C}_{26} \mathrm{H}_{23} \mathrm{~F}_{5} \mathrm{~N}_{2} \mathrm{O}_{2}$ 490.2; found 491.17 [M +1]; IR cm ${ }^{-1}$ : 1683 (CO).

$\mathrm{N}$-(3-Fluorophenyl)-N-(1-(perfluorobenzyl)piperidin-4-yl)-2-phenoxyacetamide (17b). Following the general procedure, benzaldehyde derivative $\mathbf{1 1}\left(\mathrm{R}_{3}=5 \times \mathrm{F}(0, m, p)\right)(89.6 \mathrm{mg}, 0.457 \mathrm{mmol})$; compound $\mathbf{6 b}(150 \mathrm{mg}$, $0.457 \mathrm{mmol})$; sodium triacetoxyborohydride $(142.29 \mathrm{mg}, 0.685 \mathrm{mmol})$ and acetic acid $(41.16 \mathrm{mg}$, $0.685 \mathrm{mmol})$ in 1,2-dichloroethane $(5 \mathrm{~mL})$ was stirred for $24 \mathrm{~h}$ at $20^{\circ} \mathrm{C}$, to furnish $\mathbf{1 7 b}(0.125 \mathrm{~g}, 54 \%)$; m.p.: $95{ }^{\circ} \mathrm{C} .{ }^{1} \mathrm{H}-\mathrm{NMR}\left(\mathrm{CDCl}_{3}, 600 \mathrm{MHz}\right): 1.42\left(\mathrm{~m}, 2 \mathrm{H}, \mathrm{CH}_{2}\right) ; 1.9\left(\mathrm{~m}, 2 \mathrm{H}, \mathrm{CH}_{2}\right) ; 2.24\left(\mathrm{~m}, 2 \mathrm{H}, \mathrm{CH}_{2}\right)$; $2.93\left(\mathrm{~m}, 2 \mathrm{H}, \mathrm{CH}_{2}\right) ; 3.69\left(\mathrm{~s}, 2 \mathrm{H}, \mathrm{CH}_{2}\right) ; 4.28\left(\mathrm{~s}, 2 \mathrm{H}, \mathrm{CH}_{2}\right) ; 4.58(\mathrm{~m}, \mathrm{H}, \mathrm{CH}) ; 6.73-7.42(\mathrm{~m}, 9 \mathrm{H}$ aromatic). ${ }^{13} \mathrm{C}-\mathrm{NMR}\left(150 \mathrm{MHz}, \mathrm{CDCl}_{3}\right) \delta$ : $30.27\left(2 \times \mathrm{CH}_{2}\right) ; 43.66\left(2 \times \mathrm{CH}_{2}\right) ; 51.79\left(\mathrm{CH}_{2}\right) ; 52.40(\mathrm{CH}) ; 67.24\left(\mathrm{CH}_{2}\right)$; 113.98 (2× CHAr); 116.90 (d, J = 19.5 Hz, CHAr); 117.60 (d, J = $21 \mathrm{~Hz}, \mathrm{CHAr}) ; 122.52$ (CHAr); 122.66 (CHAr); 123.18 (C); 125.95 (CHAr); 127.69 (2× CHAr); 130.66 (CHAr); 131.15 (C); 131.29 (d, J = $10.5 \mathrm{~Hz}$, CHAr); $137.81(2 \times$ C); $138.26(2 \times$ C); 146.67 (C); $153.70(\mathrm{C}) ; 162$ (d, J = $249 \mathrm{~Hz}, \mathrm{C}) ; 167.77$ (C). ESI $(\mathrm{m} / \mathrm{z})$ : calcd for $\mathrm{C}_{26} \mathrm{H}_{25} \mathrm{Cl}_{2} \mathrm{FN}_{2} \mathrm{O}_{2}$ 508.2; found $509.11[\mathrm{M}+1]$; $\mathrm{IR} \mathrm{cm}^{-1}$ : 1676 (CO).

2-(2-Chlorophenoxy)-N-(1-(perfluorobenzyl)piperidin-4-yl)-N-phenylacetamide (17c). Following the general procedure, benzaldehyde derivatives $11\left(\mathrm{R}_{3}=5 \mathrm{xF}(0, m, p)\right)(85.57 \mathrm{mg} ; 0.435 \mathrm{mmol})$; compound $\mathbf{6 c}$ $(150 \mathrm{mg}, 0.435 \mathrm{mmol})$; sodium triacetoxyborohydride $(138 \mathrm{mg}, 0.653 \mathrm{mmol})$ and acetic acid $(39.2 \mathrm{mg}$, $0.653 \mathrm{mmol})$ in 1,2-dichloroethane $(5 \mathrm{~mL})$ was stirred for $24 \mathrm{~h}$ at $20^{\circ} \mathrm{C}$. Yield of $17 \mathrm{c}: 0.139 \mathrm{~g}(61 \%)$; m.p.: $78{ }^{\circ} \mathrm{C} ;{ }^{1} \mathrm{H}-\mathrm{NMR}\left(\mathrm{CDCl}_{3}, 600 \mathrm{MHz}\right): 1.42\left(\mathrm{~m}, 2 \mathrm{H}, \mathrm{CH}_{2}\right) ; 1.79\left(\mathrm{~m}, 2 \mathrm{H}, \mathrm{CH}_{2}\right) ; 2.24\left(\mathrm{~m}, 2 \mathrm{H}, \mathrm{CH}_{2}\right)$; $2.93\left(\mathrm{~m}, 2 \mathrm{H}, \mathrm{CH}_{2}\right) ; 3.69\left(\mathrm{~s}, 2 \mathrm{H}, \mathrm{CH}_{2}\right) ; 4.28\left(\mathrm{~s}, 2 \mathrm{H}, \mathrm{CH}_{2}\right) ; 4.58(\mathrm{~m}, \mathrm{H}, \mathrm{CH}) ; 6.73-7.42$ (m, $9 \mathrm{H}$ aromatic). ${ }^{13} \mathrm{C}-\mathrm{NMR}\left(150 \mathrm{MHz}, \mathrm{CDCl}_{3}\right)$ : $: 30.27\left(2 \times \mathrm{CH}_{2}\right) ; 48.64\left(\mathrm{CH}_{2}\right) ; 52.18\left(2 \times \mathrm{CH}_{2}\right) ; 52.40(\mathrm{CH}) ; 67.24\left(\mathrm{CH}_{2}\right)$; 113.85 (2× CHAr); 122.51 (CHAr); 123.18 (C); 127.61 (2× CHAr); 129.61 (CHAr); 130.11 (CHAr); 130.56 (2× CHAr); 136.27 (C); 136.50 (2× C); 138.47 (2× C); 146.49 (C); 146.31 (C); 153.88 (C); 167.77 (C). ESI $(\mathrm{m} / \mathrm{z})$ : calcd for $\mathrm{C}_{26} \mathrm{H}_{22} \mathrm{ClF}_{5} \mathrm{~N}_{2} \mathrm{O}_{2}$ 524.1; found 525.13 [M + 1]; $\mathrm{IR} \mathrm{cm}^{-1}$ : $1683(\mathrm{CO})$. 
2-(2-Chlorophenoxy)-N-(3-fluorophenyl)-N-(1-(perfluorobenzyl) piperidin-4-yl) acetamide (17d). Following the general procedure, benzaldehyde derivative $11\left(\mathrm{R}_{3}=5 \mathrm{xF}(o, m, p)\right)(81.19 \mathrm{mg}, 0.4142 \mathrm{mmol})$; compound $6 \mathbf{d}$ (150 mg, $0.4142 \mathrm{mmol})$; sodium triacetoxyborohydride (131.6 mg, $0.6213 \mathrm{mmol}$ ) and acetic acid $(37.3 \mathrm{mg}, 0.6213 \mathrm{mmol})$ in 1,2-dichloroethane $(5 \mathrm{~mL})$ was stirred for $24 \mathrm{~h}$ at $20^{\circ} \mathrm{C}$ to provide 17d (0.1324 g, 59\%); m.p.: $125^{\circ} \mathrm{C} ;{ }^{1} \mathrm{H}-\mathrm{NMR}\left(\mathrm{CDCl}_{3}, 600 \mathrm{MHz}\right): 1.42\left(\mathrm{~m}, 2 \mathrm{H}, \mathrm{CH}_{2}\right) ; 1.9\left(\mathrm{~m}, 2 \mathrm{H}, \mathrm{CH}_{2}\right)$; $2.24\left(\mathrm{~m}, 2 \mathrm{H}, \mathrm{CH}_{2}\right) ; 2.93\left(\mathrm{~m}, 2 \mathrm{H}, \mathrm{CH}_{2}\right) ; 3.69\left(\mathrm{~s}, 2 \mathrm{H}, \mathrm{CH}_{2}\right) ; 4.28\left(\mathrm{~s}, 2 \mathrm{H}, \mathrm{CH}_{2}\right) ; 4.58(\mathrm{~m}, \mathrm{H}, \mathrm{CH}) ; 6.73-7.42$ (m, 8H aromatic). ${ }^{13} \mathrm{C}-\mathrm{NMR}\left(150 \mathrm{MHz}, \mathrm{CDCl}_{3}\right) \delta: 30.27\left(2 \times \mathrm{CH}_{2}\right) ; 43.66\left(2 \times \mathrm{CH}_{2}\right) ; 51.79\left(\mathrm{CH}_{2}\right) ; 52.40$ (CH); $67.24\left(\mathrm{CH}_{2}\right) ; 113.98$ (CHAr); 116.90 (d, J = 19.5 Hz, CHAr); 117.60 (d, J = 21 Hz, CHAr); 122.52 (CHAr); 122.66 (C); 123.18 (C); 125.95 (CHAr); 127.69 (CHAr); 130.66 (CHAr); 131.15 (C); 131.29 (d, $J=10.5 \mathrm{~Hz}, \mathrm{CHAr}) ; 137.81$ (2× C); 138.26 (2× C); 146.67 (C); 153.70 (C); 162 (d, J = 249 Hz, C); 167.77 (C). ESI ( $m / z)$ : calcd for $\mathrm{C}_{26} \mathrm{H}_{22} \mathrm{ClF}_{5} \mathrm{~N}_{2} \mathrm{O}_{2}$ 542.1; found 543.13 [M + 1]; IR cm ${ }^{-1}$ : 1695 (CO).

\subsection{Biological Assays}

\subsubsection{Antiplasmodial Assay}

The antimalarial activity of extracts/compounds was evaluated against P. falciparum 3D7 and P. falciparum W2 strains, using the fluorescence-based SYBR Green I assay approach in 96-well microplates as described by Smilkstein et al. [34] with some modifications. Positive control wells for each assay contained no inhibitor while negative controls contained Chloroquine (CQ). The CQ molecule was provided from World Wide Antimalarial Resistance Network (wwarn Network). Experiments were run in duplicate with both test and control drugs employed at varying concentrations. Stock solutions (extracts) were prepared in dimethyl-sulfoxide (DMSO) and diluted with culture medium to give a maximum DMSO concentration of $0.5 \%$ in a final well volume of $200 \mu \mathrm{L}$ containing $1 \%$ parasitemia and $2.5 \%$ haematocrit. Extracts and negative control (chloroquine (CQ)) were prepared by two-fold dilution, in a dose-titration range of $0.098-100 \mu \mathrm{g} / \mathrm{mL}$, to obtain 11 concentrations each, in duplicate. The concentrations used for CQ were between 0.5 and $1000 \mathrm{nM}$. After $48 \mathrm{~h}$ incubation, the plates were subjected to 3 freeze thaw cycles to achieve complete hemolysis. The parasite lysis suspension was diluted 1:5 in SYBR Green I lysis buffer $(10 \mathrm{mM} \mathrm{NaCl}, 1 \mathrm{mM}$ Tris $\mathrm{HCl}$ pH 8, $2.5 \mathrm{mM}$ EDTA $\mathrm{pH} 8,0.05 \% \mathrm{SDS}, 0,01 \mathrm{mg} / \mathrm{mL}$ proteinase $\mathrm{K}$ and 10X SYBR Green I). Incorporation of SYBR Green I in parasite DNA amplification was measured using the Master epRealplex cycler ${ }^{\circledR}$ (Eppendorf, Montesson, France) according the following program to increase the SYBR green incorporation: $90^{\circ} \mathrm{C}$ for $1 \mathrm{~min}$, decrease in temperature from $90^{\circ} \mathrm{C}$ to $10^{\circ} \mathrm{C}$ for $5 \mathrm{~min}$ with reading the fluorescence $10{ }^{\circ} \mathrm{C}$ for $1 \mathrm{~min}$ and a new reading at $10^{\circ} \mathrm{C}$ for $2 \mathrm{~min}$. The $\mathrm{IC}_{50}$ was calculated by nonlinear regression using icestimator website 1.2 version: http://www.antimalarial-icestimator.net/MethodIntro.htm.

\subsubsection{Cytotoxicity on HUVEC}

HUVEC cells were cultured in Gibco ${ }^{\mathrm{TM}}$ RPMI 1640 medium (Life Technologies, Saint-Aubin, France) complemented with 10\% Fetal Bovine Serum and $1 \mathrm{mM}$ L-glutamine (Sigma-Aldrich, Lesquin, France) and incubated in $5 \% \mathrm{CO}_{2}$ at $37^{\circ} \mathrm{C}$. The cytotoxicity of extracts was evaluated using the SYBR Green I assay as previously described. HUVEC were seeded in a 96-well plate at 100,000 cells/well and incubated for $24 \mathrm{~h}$ to adhere. After discarding the old medium, the cells were incubated in the medium containing eight concentrations $(0.78-100 \mu \mathrm{g} / \mathrm{mL})$ of each extract in duplicate. After $48 \mathrm{~h}$ incubation, cells were visualized using an inverted microscope to check their morphology or the cell viability. The medium was subsequently removed and replaced by lysis buffer without SYBR Green I and the plates were subjected to 3 freeze-thaw cycles. The cell lysis suspension was diluted 1:2 in SYBR Green I lysis buffer. The incorporation of SYBR Green I in cell DNA and the $\mathrm{IC}_{50}$ analysis were obtained as previously. 


\section{Conclusions}

In this study, we have prepared a small library of new nitrogen heterocycles displaying piperidine scaffolds using a flexible synthetic approach. Eighteen new derivatives were prepared in good yield. The antimalarial activity of these compounds has been described. The compounds were tested against P. falciparum 3D7 strains and W2. The best result is observed with the compounds $\mathbf{1 3 b}$ against the 3D7 strain and 12a against the $\mathrm{W} 2$ one with a selectivity index greater than chloroquine. We observed that modification with different $R$ groups, for example compound $12 a\left(R_{1}=R_{2}=R_{3}=H\right)$ in $13 b\left(R_{1}=F\right.$, $\mathrm{R}_{2}=\mathrm{H}, \mathrm{R}_{3}=\mathrm{Br}$ ) significantly modulated the activity of the tested molecules. These molecules could be further optimized to provide good malaria drug candidates.

Author Contributions: R.S. performed the synthetic, drew the molecules and searched the literatures, A.G. and C.C. designed the target compounds, provided guidance to optimization the synthesis process and wrote paper, S.C. conceived and performed the biological assay. All authors have read and agreed to the published version of the manuscript.

Funding: This work was supported by the French cooperation.

Acknowledgments: We thank Université de REIMS, Institut de chimie moléculaire de Reims (ICMR), France, for recording NMR, Université Paris XI, France, for bioactive tests and the French cooperation for the attribution of the bourse for Rokhyatou Seck.

Conflicts of Interest: The authors declare no conflicts of interest.

\section{References}

1. World Health Organization. World Malaria Report; World Health Organization: Geneva, Switzerland, 2017.

2. Noedl, H. The need for new antimalarial drugs less prone to resistance. Curr. Pharm. Des. 2013, 19, $266-269$. [CrossRef] [PubMed]

3. Njuguna, N.; Ongarora, D.S.B.; Chibale, K. Artemisin derivatives: A patent review (2006-present). Expert. Opin. Ther. Pat. 2012, 22, 1179-1203. [CrossRef] [PubMed]

4. Ongarora, D.S.B.; Strydom, N.; Wicht, K.; Njoroge, M.; Wiesner, L.; Egan, T.J.; Wittlin, S.; Jurva, U.; Masimirembwa, C.M.; Chibale, K. Antimalarial benzoheterocyclic 4-aminoquinolines: Structure-activity relationship, in vivo evaluation, mechanistic and bioactivation studies. Bioorg. Med. Chem. 2015, 23, 5419-5432. [CrossRef] [PubMed]

5. Toshio, H.; Fumihiro, I. Shin-Ichi, Y. Direct Arylation of 2-Pyridones; Photostimulated SRN1 Reaction between Cesium Phenoxides and Chloro-2-pyridones. Heterocycles 2000, 52, 253-260.

6. Kohnen-Johannsen, K.L.; Kayser, O. Tropane Alkaloids: Chemistry, Pharmacology, Biosynthesis and Production. Molecules 2019, 24, 796. [CrossRef]

7. Huang, J.P.; Fang, C.; Ma, X.; Wang, L.; Yang, J.; Luo, J.; Yan, Y.; Zhang, Y.; Huang, S.X. Tropane alkaloids biosynthesis involves an unusual type III polyketide synthase and non-enzymatic condensation. Nat. Commun. 2019, 10, 4036. [CrossRef]

8. Santos, A.S.; Lukens, K.A.; Coelho, L.; Noguero, F.; Wirth, D.F.; Mazitschek, R.; Moreira, R.; Paulo, A. Exploring the 3-piperidin-4-yl-1H-indole scaffold as a novel antimalarial chemotype. Eur. J. Med. Chem. 2015, 102, 320-333. [CrossRef]

9. Ishiguro, Y.; Kubota, T.; Ishiuchi, K.; Fromont, J.; Kobayashi, J. A novel piperidine alkaloid from an Okinawan marine sponge Plakortis sp. Tetrahedron Lett. 2009, 50, 3202-3204. [CrossRef]

10. Kubizna, P.; Spanik, I.; Kozisek, J.; Szolcsanyi, P. Synthesis of 2,6-disubstituted piperidine alkaloids from ladybird beetles Calvia 10-guttata and Calvia 14-guttata. Tetrahedron 2010, 66, 2351-2355. [CrossRef]

11. Gassama, A.; Ernenwein, C.; Hoffmann, N. Photochemical Key Steps in the Synthesis of Surfactants; from Furfural-Derived Intermediates. ChemSusChem 2009, 2, 1130-1137. [CrossRef]

12. Weis, R.; Schweiger, K.; Faist, J.; Rajkovic, E.; Kungl, A.J.; Fabian, W.M.F.; Schunack, W.; Seebacher, W. Antimycobacterial and H1-antihistaminic activity of 2-substituted piperidine derivatives. Bioorg. Med. Chem. 2008, 16, 10326-10331. [CrossRef] [PubMed]

13. Dambuza, N.S.; Smith, P.; Evans, A.; Norman, J.; Taylor, D.; Andayi, A.; Egan, T.; Chibale, K.; Wiesner, L. Antiplasmodial activity, in vivo pharmacokinetics and anti-malarial efficacy evaluation of hydroxypyridinone hybrids in a mouse model. Malar. J. 2015, 14, 505. [CrossRef] [PubMed] 
14. Sun, H.; Scott, O.D. Metabolism of 4-Aminopiperidine Drugs by Cytochrome P450s: Molecular and Quantum Mechanical Insights into Drug Design. Med. Chem. Lett. 2011, 2, 638-643. [CrossRef] [PubMed]

15. Heringa, M. Review on raloxifene: Profile of a selective estrogen receptor modulator. Int. J. Clin. Pharmacol. Ther. 2003, 41, 331-345. [CrossRef] [PubMed]

16. Vogel, V.; Constantino, J.P.; Wickerman, L. Effects of tamoxifen vs raloxifene on the risk of developing invasive breast cancer and other disease outcomes: The NSABP Study of Tamoxifen and Raloxifene. JAMA 2006, 295, 2727-2741. [CrossRef]

17. Wei, X.; Nieves, K.; Rodríguez, A.D. Neopetrosiamine A, biologically active bis-piperidine alkaloid from the Caribbean Sea sponge Neopetrosia proxima. Bioorg. Med. Chem. Lett. 2010, 20, 5905-5908. [CrossRef] [PubMed]

18. Varty, G.B.; Cohen-Williams, M.E.; Hunter, J.C. The antidepressant-like effects of neurokinin NK1 receptor antagonists in a gerbil tail suspension test. Behav. Pharmacol. 2003, 14, 87-95. [CrossRef]

19. Varty, G.B.; Cohen-Williams, M.E.; Morgan, C.A. The gerbil elevated plus-maze II: Anxiolytic-like effects of selective neurokinin NK1 receptor antagonists. Neuropsychopharmacology 2002, 27, 371-379. [CrossRef]

20. Watanabe, Y.; Asai, H.; Ishii, T.; Kiuchi, S.; Okamoto, M.; Taniguchi, H.; Nagasaki, M.; Saito, A. Pharmacological characterization of T-2328, 2-fluoro-4'-methoxy-3'-[[[(2S,3S)-2-phenylpiperidinyl]-amino]methyl]-[1,1'biphenyl]-4-carbonitrile dihydrochloride, as a brain-penetrating antagonist of tachykinin NK1 receptor. J. Pharm. Sci. 2008, 106, 121-127. [CrossRef]

21. Watson, P.S.; Jiang, B.; Scott, B. A Diastereoselective Synthesis of 2.4-Disubstituted Piperidines: Scaffolds for Drug Discovery. Org. Lett. 2000, 2, 3679-3681. [CrossRef]

22. Padmanilayam, M.; Scorneaux, B.; Dong, Y.; Chollet, J.; Matile, H.; Charman, S.A.; Creek, D.J.; Charman, W.N.; Tomas, S.T.; Scheurer, C.; et al. Antimalarial activity of N-alkyl amine, carboxamide, sulfonamide and urea derivatives of a dispiro-1,2,4-trioxolane piperidine. Bioorg. Med. Chem. Lett. 2006, 16, 5542-5545. [CrossRef] [PubMed]

23. Meyers, M.J.; Anderson, E.J.; McNitt, S.A.; Krenning, T.M.; Singh, M.; Xu, J.; Zeng, W.; Qin, L.; Xu, W.; Zhao, S.; et al. Evaluation of spiropipéridine hydantoins as a novel class of antimalarial agent. Bioorg. Med. Chem. 2015, 23, 5144-5150. [CrossRef] [PubMed]

24. Misra, M.; Pandey, S.K.; Pandey, V.P.; Pandey, J.; Tripathi, R.; Tripathi, R.P. Organocatalyzed highly atom economic one pot synthesis of tetrehydropyridines as antimalarials. Bioorg. Med. Chem. 2009, 17, 625-633. [CrossRef] [PubMed]

25. Sabbani, S.; Stocks, P.A.; Ellis, G.L.; Davies, J.; Hedenstrom, E.; Ward, S.A. O'Neill, P.M. Piperidine dispiro-1,2,4-trioxane analogues. Bioorg. Med. Chem. Lett. 2008, 18, 5804-5808. [CrossRef]

26. Kikuchi, H.; Tasaka, H.; Hirai, S.; Takaya, Y.; Iwabuchi, Y.; Ooi, H.; Hatakeyama, S.; Kim, H.S.; Wataya, Y.; Oshima, Y. Potent Antimalarial Febrifugine Analogues Against the Plasmodium Malaria Parasite. J. Med. Chem. 2002, 45, 2563-2570. [CrossRef]

27. Gassama, A.; Diatta, A. Synthesis of N-Substituted piperidines from piperidone. J. Soc. Ouest-Afr. Chim. 2015, 39, 31-40.

28. Amed, F.; Magid, A.; Cynthia, A.; Kenneth, M.; Carson, G. Reductive amination of aldehydes and ketones by using sodium triacetoxyborohydride. Tetrahedron Lett. 1990, 31, 5595-5598. [CrossRef]

29. Borch, R.F.; Bernstein, M.D.; Durst, H.D. Cyanohydridoboration anion as a selective reducing agent. J. Am. Chem. Soc. 1971, 93, 2897-2904. [CrossRef]

30. Morandi, G.; Kebir, N.; Campistron, I.; Gohier, F.; Laguerre, A.; Pilard, J.F. Direct selective reductive amination of carbonyl telechelic oligoisoprenes: Elaboration of promising tri and tetrafunctionalized oligoisooprene intermediates. Tetrahedron Lett. 2007, 48, 7726-7730. [CrossRef]

31. Khan, S.N.; Bae, S.Y.; Kim, H.S. A highly stereoselective reductive amination of 3-ketosteroid with amines: Improved synthesis of $3 \alpha$-aminosteroids. Tetrahedron Lett. 2005, 46, 7675-7678. [CrossRef]

32. Adachi, K.; Tsuru, E.; Banjyo, S.E.K.; Yamashita, T. Selective BH 3-Reduction of Amide Carbonyl Groups of Lithium Salts of N-t-Butoxycarbonyl (S)-O-Benzyl Tyrosyl (S)-Proline and N,N'-Ethylene-Bridged Dipeptides. Synthesis 1998, 11, 1623-1626. [CrossRef] 
33. Beamson, G.; Papworth, A.J.; Philipps, C.; Smith, A.M.; Whyman, R. Selective hydrogenation of amides using Rh/Mo catalysts. J. Cat. 2010, 93, 269. [CrossRef]

34. Komlaga, G.; Genta-Jouve, G.; Cojean, S.; Dickson, R.T.; Mensah, M.L.K.; Loiseau, P.M.; Champy, P.; Beniddir, M.A. Antiplasmodial Securinega alkaloids from Phyllanthus fraternus: Discovery of natural (+)allonorsecurinine. Tetrahedron Lett. 2017, 58, 3754-3756. [CrossRef]

Sample Availability: Samples of the compounds are not available from the authors.

(C) 2020 by the authors. Licensee MDPI, Basel, Switzerland. This article is an open access article distributed under the terms and conditions of the Creative Commons Attribution (CC BY) license (http://creativecommons.org/licenses/by/4.0/). 